WSRC-STI-2007-00467

August 30, 2007

WSRC-STI-2007-00467

\title{
Comparisons for RAMS Models (v3a, v4.3, and v6.0)
}

Washington Savannah River Company Savannah River Site

Aiken, SC 29808

Prepared for the U.S. Department of Energy under Contract No. DE-AC09-96SR18500 


\section{Disclaimer}

This report was prepared as an account of work sponsored by an agency of the United States Government. Neither the United States Government nor any agency thereof, nor any of their employees, makes any warranty, express or implied, or assumes any legal liability or responsibility for the accuracy, completeness, or usefulness of any information, apparatus, product, or process disclosed, or represents that its use would not infringe privately owned rights. Reference herein to any specific commercial product, process, or service by trade name, trademark, manufacturer, or otherwise does not necessarily constitute or imply its endorsement, recommendation, or favoring by the United States Government or any agency thereof. The views and opinions of authors expressed herein do not necessarily state or reflect those of the United States Government or any agency thereof. 


\section{Comparisons for RAMS Models (v3a, v4.3, and v6.0)}

Kuo-FüChen, Author, NHSD/NTS/ATG

Wachinotnn Savannah River Comnanv

R. L. Buckley, Technłcal Review, NHSD/NTS/ATG

Washington Savannah River Company

Approved by:

C,H. Hunter; Mánager, NHSD/NTS/ATG

Washington Savannah River Company

Prepared for the U.S. Department of Energy under Contract no. DE-AC09-96SR18500 
WSRC-STI-2007-00467

August 30, 2007

This page intentionally left blank.

- iv - 


\section{EXECUTIVE SUMMARY}

The Regional Atmospheric Modeling System (RAMS) is an atmospheric numerical model developed by scientists at Colorado State University and the ASTER Division of Mission Research Corporation for simulating and forecasting meteorological phenomena. RAMS v3a and v4.3 are being used by the Savannah River National Laboratory (SRNL) as an operational tool for weather forecast and emergency response for the Savannah River Site (SRS).

ATmospheric, Meteorological, and Environmental Technologies (ATMET) is now the proprietor of RAMS. The latest upgrade (v6.0) was officially released on January 11, 2006. ATG plans to eventually replace the RAMS v3a and v4.3 with the RAMS v6.0 for operational site forecasting if the newest version provides a significant improvement in the numerical forecast. A study to compare the three model (v3a, v4.3 and v6.0) results with respect to surface stations observations was conducted and is the subject of this report. Two cases were selected for simulation by these three RAMS models. One simulation started at $0 \mathrm{Z}$ on April 3, 2007 and represents a warm weather case (high temperature of $26^{\circ} \mathrm{C}$ and low temperature of $16^{\circ} \mathrm{C}$ ) at SRS, while the other simulation started at $0 \mathrm{Z}$ on April 7, 2007 and represents a cold weather case (high temperature of $9^{\circ} \mathrm{C}$ and low temperature of $-1^{\circ} \mathrm{C}$ ) at SRS. The wind speeds, wind directions, temperatures and the dew point temperatures predicted by the three RAMS models were interpolated to 46 surface observation locations. The interpolated results were compared with the observation data. Statistically, the differences between the three model results were very small. For the present configurations, the predictions from RAMS v6.0 are no better than the older models with the exception of wind direction. The proposed path forward would be to fine tune the RAMS v6.0 model input parameters to improve the predictions. This should also provide insights into current weaknesses in all RAMS versions. 
WSRC-STI-2007-00467

August 30, 2007

\section{TABLE OF CONTENTS}

1. INTRODUCTION 1

2. RAMS v6.0 UPGRADES 1

3. RAMS MODEL SIMULATION CHARACTERISTICS 2

4. OBSERVATION DATA 2

5. STATISTICAL MEASURES

6. RESULTS 4

6.1 Comparisons as a Function of Space and Time 4

6.1.1 Wind Speed 4

6.1.2 Wind Direction 5

6.1.3 Temperature 5

6.1.4 Dew Point Temperature 5

6.2 Statistical Comparisons $\quad 5$

7. CONCLUSIONS

8. ACKNOWLEDGMENT 6

$\begin{array}{ll}\text { REFERENCES } & 7\end{array}$ 


\section{LIST OF TABLES}

Table 1: Percent of the Data Points with Absolute Wind Direction Errors within the Stated Angle

Table 2: Mean Errors and Standard Deviations

\section{LIST OF FIGURES}

Figure 1: Model Domain Map and the Observation Stations $\quad 10$

Figure 2: Model Comparisons at Station SRS 11

Figure 3: Model Comparisons at Station KAGS 12

Figure 4: Model Comparisons at Station KDNL 13

Figure 5: Model Comparisons at Station KMCN 14

Figure 6: Model Comparisons at Station KATL 15

Figure 7: Model Comparisons at Station KCAE 16

Figure 8: Model Comparisons at Station KCHS 17

Figure 9: Mean Absolute Errors for Wind Speed Predictions (Averaged over all Stations $\begin{array}{ll}\text { and for Both Cases) } & 18\end{array}$

Figure 10: Mean Absolute Errors for Wind Direction Predictions (Averaged over all Stations $\begin{array}{ll}\text { and for Both Cases) } & 18\end{array}$

Figure 11: Mean Absolute Errors for Temperature Predictions (Averaged over all Stations and for Both Cases)

Figure 12: Mean Absolute Errors for Dew Point Temperature Predictions (Averaged over all Stations and for Both Cases)

Figure 13: Histogram for Wind Direction Absolute Errors (Forecast Hours 12 to 48 for all Stations and for Both Cases )

Figure 14: Mean Errors and Standard Deviations $( \pm \sigma)$ for Wind Speed Predictions (Forecast Hours 12 to 48 and all Stations)

Figure 15: Mean Errors and Standard Deviations $( \pm \sigma)$ for Wind Direction Predictions (Forecast Hours 12 to 48 and all Stations)

Figure 16: Mean Errors and Standard Deviations $( \pm \sigma)$ for Temperature Predictions (Forecast Hours 12 to 48 and all Stations)

Figure 17: Mean Errors and Standard Deviations $( \pm \sigma)$ for Dew Point Temperature Predictions (Forecast Hours 12 to 48 and all Stations)

Figure 18: Histogram for Wind Direction Absolute Errors (Forecast Hours 12 to 24 for all Stations and for Both Cases)

Figure 19: Mean Errors and Standard Deviations $( \pm \sigma)$ for Wind Speed Predictions (Forecast Hours 12 to 24 and all Stations)

Figure 20: Mean Errors and Standard Deviations $( \pm \sigma)$ for Wind Direction Predictions (Forecast Hours 12 to 24 and all Stations)

Figure 21: Histogram for Observed Wind Direction (46 Observation Stations Hours 12 to 24) 28

Figure 22: Mean Errors and Standard Deviations $( \pm \sigma)$ for Temperature Predictions (Forecast Hours 12 to 24 and all Stations)

Figure 23: Mean Errors and Standard Deviations $( \pm \sigma)$ for Dew Point Temperature Predictions (Forecast Hours 12 to 24 and all Stations) 


\section{INTRODUCTION}

The Regional Atmospheric Modeling System (RAMS) [1] is an atmospheric numerical model developed by scientists at Colorado State University and the ASTER Division of Mission Research Corporation for simulating and forecasting meteorological phenomena. RAMS v3a and v4.3 are being used by the Savannah River National Laboratory (SRNL) as an operational tool for weather forecast and emergency response for the Savannah River Site (SRS). ATmospheric, Meteorological, and Environmental Technologies (ATMET) is now the proprietor of RAMS. The latest upgrade (v6.0) was officially released on January 11, 2006 (http://bridge.atmet.org/users/software.php). ATG plans to eventually replace the RAMS v3a and v4.3 with the RAMS v6.0 for operational site forecasting if the newest version provides a significant improvement in the numerical forecast. A study to compare these three model (v3a, v4.3 and v6.0) results with respect to the surface stations observations was conducted and is the subject of this report. Two cases were selected for simulation by the three RAMS models. One simulation started at $0 \mathrm{Z}$ on April 3, 2007 and represents a warm weather case (high temperature of $26^{\circ} \mathrm{C}$ and low temperature of $16^{\circ} \mathrm{C}$ ) at SRS, while the other simulation started at $0 \mathrm{Z}$ on April 7, 2007 and represents a cold weather case (high temperature of $9^{\circ} \mathrm{C}$ and low temperature of $-1^{\circ} \mathrm{C}$ ) at SRS. The wind speeds, wind directions, temperatures and the dew point temperatures predicted by the three RAMS models were interpolated to 46 surface observation locations. The interpolated results were compared with the observation data. The results of this study will provide input for decisions regarding migration to RAMS v6.0.

\section{RAMS v6.0 UPGRADES}

The major changes of the RAMS v6.0 are listed below [4].

A. Code structure changes

RAMS v6.0 uses explicit variable types to help eliminate bugs, and no longer uses the monolithic "A" array. The sizes of subroutines were reduced by dividing the subroutine into multiple subroutines with smaller sizes for ease of maintenance. The Fortran 90 module concept was also implemented.

B. File format changes

All intermediate and output files are now written in the Hierarchical Data Format (HDF5).

\section{New features}

A new Four Dimensional Data Assimilation (FDDA) observational data assimilation scheme was implemented (not used in this study), which is based on "direct" nudging to the observations. The Kain-Fritsch cumulus parameterization, which is a modified 
version of the Fifth-Generation Penn State/NCAR Mesoscale Model (MM5)/ Weather Research Forecasting (WRF) scheme, was added to the upgraded RAMS v6.0. The new RAMS v6.0 has added abilities to start a new run from the state file of a previous run, while also allowing the user to modify the grid structure for this new run.

\section{Modified schemes}

There are additional options to control the FDDA analysis nudging. The Land Atmosphere Ecosystem Feedback version 2 (LEAF2) is updated to version 3 (LEAF3). LEAF3 uses the Normalized Difference Vegetation Index (NDVI) for computing leaf area index, vegetation fractional cover, vegetation albedo, and roughness height. The vegetation categories of LEAF2 which came from the Biosphere-Atmosphere Transfer Scheme (BATS) and the Land Data Assimilation System (LDAS), are consolidated from $30+$ to 20 categories, and the parameter values were composited between BATS, LDAS, Simple Biosphere Model Version 2 (SiB2), and other values.

\section{RAMS MODEL SIMULATION CHARACTERISTICS}

The same geometrical domain and grid cell sizes are used in the three model simulations (RAMS v3a, v4.3 and v6.0). The horizontal domain $(800 \times 760 \mathrm{~km})$ centered at the SRS covers the states of South Carolina and Georgia, as shown in Figure 1. The horizontal grid cell size is uniform and is kept at $20 \mathrm{~km}$. The vertical domain size is $16.9 \mathrm{~km}$ and is divided into 30 cells with variable cell sizes. The cell vertical size near the ground surface is $\sim 45 \mathrm{~m}$, which gradually increases to $\sim 1 \mathrm{~km}$ near the top of the model domain. This provides finer resolution near the ground to capture boundary layer structure. Two cases were selected for simulation. One simulation started at $0 \mathrm{Z}$ on April 3, 2007 and represents a warm weather case (high temperature of $26^{\circ} \mathrm{C}$ and low temperature of $16^{\circ} \mathrm{C}$ ) at SRS, while the other simulation started at $0 \mathrm{Z}$ on April 7, 2007 and represents a cold weather case (high temperature of $9^{\circ} \mathrm{C}$ and low temperature of $-1^{\circ} \mathrm{C}$ ) at SRS. The simulations for both cases generated a 48-hour forecast, but the first 12-hours of the simulation were discarded for the model to 'spin up' a realistic boundary layer. The initial and boundary conditions used the analyzed dynamic meteorological fields generated by the North American Model (NAM) large-scale models, available from the National Center for Environmental Prediction (NCEP).

\section{OBSERVATION DATA}

The observed surface data are obtained from 45 National Weather Service (NWS) stations and the SRS Central Climatology tower, as shown in Figure 1. The NWS station data, at 10 meter above ground level, are 2-minute averages taken at the beginning of the hour and are available at 1-hour increments. The SRS Central Climatology tower data, at 18 meter above ground level, are 15-minute averages and are available at 15-minute increments. The various evaluation and visualization utilities that come with the RAMS installations, were used to interpolate the RAMS output data to the location of the observation stations. These include the Visualization and Analysis Package (VAN) [5] 
for the RAMS v3a output, RAMS/HYPACT Evaluation and Visualization Utilities (REVU) v2.3.1 [6] for the RAMS v4.3 output, and REVU v2.5 [7] for the RAMS v6.0 output.

\section{STATISTICAL MEASURES}

For both of these two simulation cases, the RAMS models simulated 48 hours and generated output field variables at a one-hour time interval. The output data for the first 12 hours were discarded. Therefore, there were 37 output times used for this study. Because there are 46 observation stations, the number of data points is $1702(37 \times 46)$ for each simulation case, or 3404 (2x1702) data points for both simulation cases.

For every observation station, wind speed, wind direction, temperature, and dew point temperature were examined. For each of these variables, simulated and observed surface data were compared. The mean relative error between simulated and observed values for each of the model versions is given by

$\overline{d_{c}^{m}}=\frac{1}{M \times N} \sum_{j=1}^{M} \sum_{i=1}^{N}\left(s_{c, j, i}^{m}-o_{c, j, i}\right)$

where $s$ is the simulated value, and $o$ is the observed value. The superscript $m$ represents which model is used (RAMS v3a, RAMS v43, or RAMS v60). The subscript $c$ represents which weather case is used (warm or cold). The subscript $j$ represents the observation station with $M$ being the total number of observation stations (46). The subscript $i$ is the time steps with $N$ being the total number of time steps (37). The value of $N$ might be less than 37 if there were observation data missing.

The overall (cold and warm weather) mean relative error is defined as

$\overline{d^{m}}=\frac{1}{2}\left(\overline{d_{\text {cold }}^{m}}+\overline{d_{\text {warm }}^{m}}\right)$.

Similarly, the mean absolute error is determined by averaging the sum of the absolute difference between the simulated and observed values for all the data points, and is defined as

$\left|\overline{d_{c}^{m}}\right|=\frac{1}{M \times N} \sum_{j=1}^{M} \sum_{i=1}^{N}\left|s_{c, j, i}^{m}-o_{c, j, i}\right|$

The overall (cold and warm weather) mean absolute error is given by:

$$
\left|\overline{d^{m}}\right|=\frac{1}{2}\left(\left|\overline{d_{\text {cold }}^{m}}\right|+\left|\overline{d_{\text {warm }}^{m}}\right|\right) .
$$


The standard deviation of the differences is given by:

$$
\sigma_{c}^{m}=\left[\frac{1}{M \times N-1} \sum_{j=1}^{M} \sum_{i=1}^{N}\left(\left(s_{c, j, i}^{m}-o_{c, j, i}\right)-\overline{d_{c}^{m}}\right)^{2}\right]^{\frac{1}{2}}
$$

The overall (cold and warm weather) standard deviation of the differences is given by:

$$
\sigma^{m}=\left[\frac{1}{M \times N \times 2-1} \sum_{c=1}^{2} \sum_{j=1}^{M} \sum_{i=1}^{N}\left(\left(s_{c, j, i}^{m}-o_{c, j, i}\right)-\overline{d_{c}^{m}}\right)^{2}\right]^{\frac{1}{2}}
$$

Because the wind direction overlaps from $0^{\circ}$ to $360^{\circ}$, the wind direction error for an individual data point is calculated as:

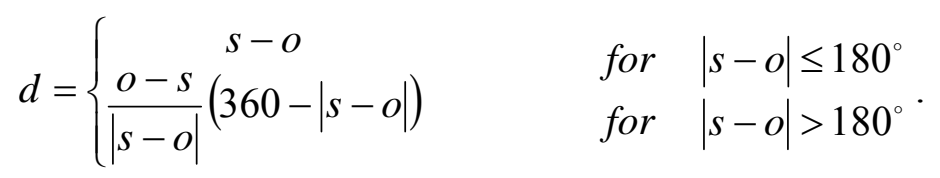

\section{RESULTS}

The horizontal wind speeds, wind directions, air temperatures, and dew point temperatures were compared between the observed and the RAMS models at 46 observation locations (Figure 1).

\subsection{Comparisons as a Function of Space and Time}

Figures 2 through 8 show the comparisons at 7 selected observation locations: SRS, KAGS (Bush Field Airport, Augusta, GA), KDNL (Daniel Field Airport, Augusta, GA), KMCN (Macon, GA), KATL (Atlanta, GA), KCAE (Columbia, SC), and KCHS (Charleston, CS), respectively. The panels on the left side of each figure correspond to the warm weather (April 3) case, while the panels on the right side indicate the results for the cold weather (April 7) case.

\subsubsection{Wind Speed}

Wind speed is a physical property that changes value rapidly with time. The observed data is measured at a point location, while the data predicted by the RAMS is a grid volume averaged quantity. In addition, the NWS station data are 2-minute averages and the SRS Central Climatology tower data are 15-minute averages, leading to quickly changing values for observed wind speed. As a result, the observed wind speeds show significant irregularities, as shown in Figures 2 through 8. However, the RAMS models calculate the mean wind speeds which inherently are characteristically smooth (due to spatial and temporal averaging), as shown in Figures 2 through 8. Therefore, the RAMS 
models do not predict the high frequency variations as measured by the observation stations. However, the RAMS models (in particular, RAMS v3a) match the trend of the observed wind speed quite well.

\subsubsection{Wind Direction}

The agreement for wind direction between the RAMS models and the observations is very good, as shown figures 2 through 8, especially for the April 7 case (more discussions in Section 6.2). Figure 5 shows the RAMS v3a prediction of the wind direction at 15:00 on April 8 for the Station KMCN drops to $7.7 \mathrm{deg}$, while the observed wind direction is around $310 \mathrm{deg}$. It should be noticed that the wind direction of $360 \mathrm{deg}$ is equivalent to $0 \mathrm{deg}$. Therefore, the actual error between the RAMS v3a prediction and the observation at 15:00 on April 8 is less than $60 \mathrm{deg}$. The same is true for the Station KATL (Figure 6).

\subsubsection{Temperature}

Figures 2 through 8 indicate that RAMS models predicted the diurnal variations of the temperatures. However, RAMS v3a model tended to capture the minimum temperatures more accurately, while RAMS v4.3 and v6.0 were closer to simulating the observed maximum. Both RAMS v4.3 and v6.0 tend to overpredict the temperatures, especially for the April 3 case.

\subsubsection{Dew Point Temperature}

Among the three RAMS models, RAMS v3a had better agreement with the observed dew point temperatures. Note that similar to temperature trends, for dew $\mathrm{p}$ [oint temperatures, RAMS v4.3 and v6.0 tend to agree more closely with each other than RAMS v3a. This is likely due to the similarity in surface parameterizations (LEAF2 and LEAF3) employed in the later RAMS versions, but not used in RAMS v3a.

\subsection{Statistical Comparisons}

Figures 9 through 12 show the mean absolute errors for the wind speed, wind direction, temperature, and dew point temperature as a function of forecast time, respectively.

There were no clear patterns that the absolute errors increase or decrease with the forecast time. Again, RAMS v4.3 and v6.0 tend to track more closely with each other in time.

The absolute error of the wind direction is divided into bins of $15^{\circ}$ each. Figure 13 shows histogram plots for the three RAMS models, while Table 1 indicates the percentage of data points in which the absolute wind direction error is less than 15,45 , and $75^{\circ}$. RAMS v6.0 performed the best, followed by RAMS v4.3, and the RAMS v3a.

Table 2 shows the mean errors and the standard deviations for the separated cases and the combined cases. The statistics are broken up into different time intervals: 12 to 24 hours, 12 to 36 hours, and 12 to 48 hours. In practice, the RAMS forecasts from hours 24 to 48 
are not as critical to the operational forecast because a new forecast cycle is generated every 12 hours. Figures 14 through 17 present the mean errors and the standard deviations for the RAMS models (data from 12 hours to 48 hours) with error bars denoting $\pm \sigma$. Figure 14 shows that for wind speed predictions, the RAMS v3a model is better than the RAMS v4.3 and v6.0 models. Figure 15, presenting the wind direction statistics, shows the RAMS v6.0 model had the best results. Figure 16 presents the temperature predictions. In both cases, RAMS v3a underpredicts the temperatures, while RAMS v4.3 and v6.0 overpredict the temperatures. For warm weather, the RAMS v3a model performed better while for cold weather, the RAMS v6.0 had the best performance for temperature predictions. Overall, the RAMS v4.3 was slightly better than the other versions (Figure 16). Dew point temperature predictions (Figure 17) indicate also that RAMS v4.3 is slightly better than the other versions. For both of these cases, RAMS v3a overpredicts dew point temperatures, while RAMS v4.3 and v6.0 both underpredict dew point temperatures. The temperatures and dew point temperatures indicate RAMS v3a predicts a cooler, moister atmosphere near the surface, while RAMS v4.3 and v6.0 predict a warmer, dryer atmosphere than observed.

Typically, the RAMS data from 12 hours to 24 hours are more critical for operational weather forecasting. Figures 18 through 23 show the statistics of RAMS data from 12 hours to 24 hours which are more relevant to the SRS operational weather forecast. A histogram of wind direction shown in Figure 18 for the data from 12 hours to 24 hours, indicates better wind direction predictions for RAMS v60. Between the RAMS v3a and v4.3, RAMS v4.3 agreed more closely with observations. Figure 20 shows all of the three RAMS models predicted wind direction for the April 7 case more accurately than for the April 3 case. This is due to less variability in observed wind direction for April 7 than for April 3, as shown by the histogram of observed wind directions for all the 46 stations and over the 12 to 24 forecast time (Figure 21). This also leads to a significantly smaller standard deviation in error for the April 7 case (Figure 20).

As expected, overall the RAMS models had better wind speed, wind direction, temperature and dew point temperature predictions for the shorter period of predictions (12 hours to 24 hours) than for the longer period of predictions (12 hours to 48 hours).

\section{CONCLUSIONS}

Two cases were selected for simulation by the RAMS v3a, RAMS v4.3 and RAMS v6.0 models. One simulation started at $0 \mathrm{Z}$ on April 3, 2007 represents a warm weather case (high temperature of $26^{\circ} \mathrm{C}$ and low temperature of $16^{\circ} \mathrm{C}$ ) at SRS, and the other simulation started at $0 \mathrm{Z}$ on April 7, 2007 represents a cold weather case (high temperature of $9^{\circ} \mathrm{C}$ and low temperature of $-1^{\circ} \mathrm{C}$ ) at SRS. The wind speeds, wind directions, temperatures and the dew point temperatures predicted by the three RAMS models were interpolated to 46 observation locations. The interpolated results were compared with the observation data. For the present configurations, the upgraded physics models of the RAMS v6.0 were not explored. As expected, the statistical differences between the three model results were very small. The predictions from RAMS v6.0 are no better than the older models except for wind direction predictions. Since wind 
direction is extremely important for emergency response applications at the SRS, this finding is encouraging. Since it is planned to use RAMS v6.0 in an operational setting, the proposed path forward is to fine tune the RAMS v6.0 model input parameters to improve the predictions. This should also provide insights into current weaknesses in all RAMS versions. More comparisons over a much longer time period would be needed to determine which model version performs best at different times of year.

\section{ACKNOWLEDGEMENT}

The author would like to extend his appreciation to Dr. Robert L. Buckley for his invaluable discussions and numerous consultations. 
References

1. Chen, Kuo-Fu, "Regional Atmospheric Modeling System (RAMS) Technical Description (U)," WSRC-TR-2005-00499, October, 2005.

2. Buckley, R. L., A. H. Weber, and J. H. Weber, 2004: Statistical Comparison of Regional Atmospheric Modelling System Forecasts with Observations. Meteorological Applications, 11 (1), 67-82

3. Buckley, R. L., C. H. Hunter, R. P. Addis, and M. J. Parker, 2007: Modeling Dispersion from Toxic Gas Released after a Train Collision in Graniteville, SC. Journal of the Air and Waste Management Association, 57, 268-278.

4. Tremback, C. J., and R. L. Walko, "RAMS Regional Atmospheric Modeling System Version 6.0, User's Guide - Introduction,” ATMET, LLC, Boulder, Colorado, 2006.

5. Walko, R. L., C. J. Tremback, and F. A. Hertenstein, "RAMS The Regional Atmospheric Modeling System Version 3a, User's Guide," ASTeR, Inc., Fort Collins, Colorado, November, 1993.

6. Tremback, C. J., R. L. Walko, and M. J. Bell, "REVU: RAMS/HYPACT Evaluation and Visualization Utilities, Version 2.3.1 User's Guide," ASTER Division, Mission Research Corporation, Fort Collins, Colorado, August 20, 2001.

7. Tremback, C. J., R. L. Walko, and M. J. Bell, "REVU: RAMS/HYPACT Evaluation and Visualization Utilities, Version 2.5 User's Guide," ATMET LLC Atmospheric, Meteorological, and Environmental Technology, Boulder, Colorado, December, 2004. 
WSRC-STI-2007-00467

August 30, 2007

Table 1. Percent of the Data Points with Absolute Wind Direction Errors within the Stated Angle

$\begin{array}{cccc}\text { Angle (deg) } & \text { RAMS3a } & \text { RAMS43 } & \text { RAMS60 } \\ 15 & 35.9 & 38.9 & 41.4 \\ 45 & 79.8 & 82.2 & 83.7 \\ 75 & 94.2 & 94.3 & 95.0\end{array}$


WSRC-STI-2007-00467

August 30, 2007

Table 2. Mean Errors and Standard Deviations

April 3, 2007 Case

\begin{tabular}{lcccccc} 
& \multicolumn{1}{c}{12 hrs to 24 hrs } & \multicolumn{2}{c}{12 hrs to 36 hrs } & \multicolumn{2}{c}{12 hrs to 48 hrs } \\
& $\begin{array}{c}\text { avg } \\
\text { error }\end{array}$ & $\begin{array}{c}\text { std } \\
\text { error }\end{array}$ & $\begin{array}{c}\text { avg } \\
\text { error }\end{array}$ & $\begin{array}{c}\text { std } \\
\text { error }\end{array}$ & $\begin{array}{c}\text { avg } \\
\text { error }\end{array}$ & $\begin{array}{c}\text { std } \\
\text { error }\end{array}$ \\
RAMS3a & -0.07 & 1.43 & 0.03 & 1.63 & 0.15 & 1.63 \\
RAMS43 & 0.25 & 1.56 & 0.72 & 1.76 & 0.68 & 1.75 \\
RAMS60 & -0.12 & 1.52 & 0.42 & 1.73 & 0.29 & 1.76 \\
& & & & & & \\
& & & & & & \\
RAMS3a & 5.52 & 55.44 & 1.28 & 47.42 & 5.98 & 42.59 \\
RAMS43 & -0.80 & 54.72 & -4.79 & 46.73 & -2.43 & 43.74 \\
RAMS60 & 1.51 & 56.41 & -1.61 & 46.95 & 1.72 & 42.85 \\
& & & & & & \\
& & & & & & \\
RAMS3a & -1.40 & 2.08 & -0.46 & 2.24 & -0.86 & 2.24 \\
RAMS43 & 0.57 & 2.43 & 1.75 & 2.53 & 1.69 & 2.45 \\
RAMS60 & 0.62 & 2.44 & 2.40 & 2.94 & 2.19 & 2.74 \\
& & & & & & \\
& & & & & & \\
RAMS3a & 0.10 & 2.44 & 0.52 & 2.24 & 1.12 & 2.38 \\
RAMS43 & -0.48 & 2.58 & -0.63 & 2.56 & -0.37 & 2.73 \\
RAMS60 & -0.75 & 2.26 & -0.97 & 2.32 & -0.79 & 2.51
\end{tabular}

April 7, 2007 Case

Wind Speed $(\mathrm{m} / \mathrm{s})$

\begin{tabular}{|c|c|c|c|c|}
\hline \multicolumn{2}{|c|}{$12 \mathrm{hrs}$ to $24 \mathrm{hrs}$} & \multicolumn{2}{|c|}{$12 \mathrm{hrs}$ to $36 \mathrm{hrs}$} & $12 \mathrm{hrs}$ to $48 \mathrm{~h}$ \\
\hline $\begin{array}{l}\text { avg } \\
\text { error }\end{array}$ & $\begin{array}{l}\text { std } \\
\text { error }\end{array}$ & $\begin{array}{l}\text { avg } \\
\text { error }\end{array}$ & $\begin{array}{l}\text { std } \\
\text { error }\end{array}$ & $\begin{array}{l}\text { avg } \\
\text { error }\end{array}$ \\
\hline-0.10 & 1.53 & 0.29 & 1.60 & -0.04 \\
\hline-0.43 & 1.58 & 0.46 & 1.81 & 0.17 \\
\hline-0.59 & 1.67 & 0.39 & 1.89 & 0.05 \\
\hline \multicolumn{5}{|c|}{ Wind Direction (deg) } \\
\hline 4.03 & 23.06 & 3.95 & 31.14 & 6.12 \\
\hline-6.47 & 21.84 & -5.10 & 26.03 & -7.79 \\
\hline-2.64 & 20.64 & -1.46 & 24.66 & -0.75 \\
\hline \multicolumn{5}{|c|}{ Temperature (C) } \\
\hline-2.43 & 1.11 & -1.27 & 2.12 & -1.93 \\
\hline-0.73 & 1.55 & 0.77 & 2.40 & 0.32 \\
\hline-1.13 & 1.52 & 1.04 & 2.86 & 0.19 \\
\hline \multicolumn{5}{|c|}{ Dew Point Temperature (C) } \\
\hline 2.41 & 1.88 & 1.59 & 2.36 & 1.37 \\
\hline 1.01 & 1.90 & -1.11 & 3.08 & -1.46 \\
\hline-0.35 & 1.50 & -2.24 & 2.75 & -2.32 \\
\hline
\end{tabular}

Combined

\begin{tabular}{cccccc}
\multicolumn{2}{c}{$\begin{array}{c}12 \text { hrs to } \\
\text { avg }\end{array}$} & hrs & \multicolumn{2}{c}{12 hrs to 36 hrs } & \multicolumn{2}{c}{12 hrs to 48 hrs } \\
error & error & avg & std & avg & std \\
-0.09 & 1.48 & 0.16 & 1.62 & 0.06 & 1.64 \\
-0.08 & 1.61 & 0.60 & 1.79 & 0.43 & 1.79 \\
-0.35 & 1.61 & 0.40 & 1.81 & 0.17 & 1.82 \\
& & & & & \\
& & & & & \\
4.68 & 40.47 & 2.60 & 40.23 & 6.04 & 38.59 \\
-4.00 & 39.75 & -4.94 & 37.95 & -4.98 & 38.26 \\
-0.83 & 40.36 & -1.54 & 37.63 & 0.55 & 36.89 \\
& & & & & \\
& & & & & \\
-1.91 & 1.75 & -0.86 & 2.22 & -1.39 & 2.33 \\
-0.07 & 2.14 & 1.27 & 2.51 & 1.02 & 2.46 \\
-0.24 & 2.22 & 1.73 & 2.98 & 1.20 & 2.94
\end{tabular}

$\begin{array}{cccccc}1.24 & 2.47 & 1.05 & 2.36 & 1.24 & 2.35 \\ 0.25 & 2.39 & -0.87 & 2.83 & -0.91 & 2.81 \\ -0.56 & 1.93 & -1.60 & 2.62 & -1.54 & 2.64\end{array}$


Figure 1. Model Domain Map and the Observation Stations

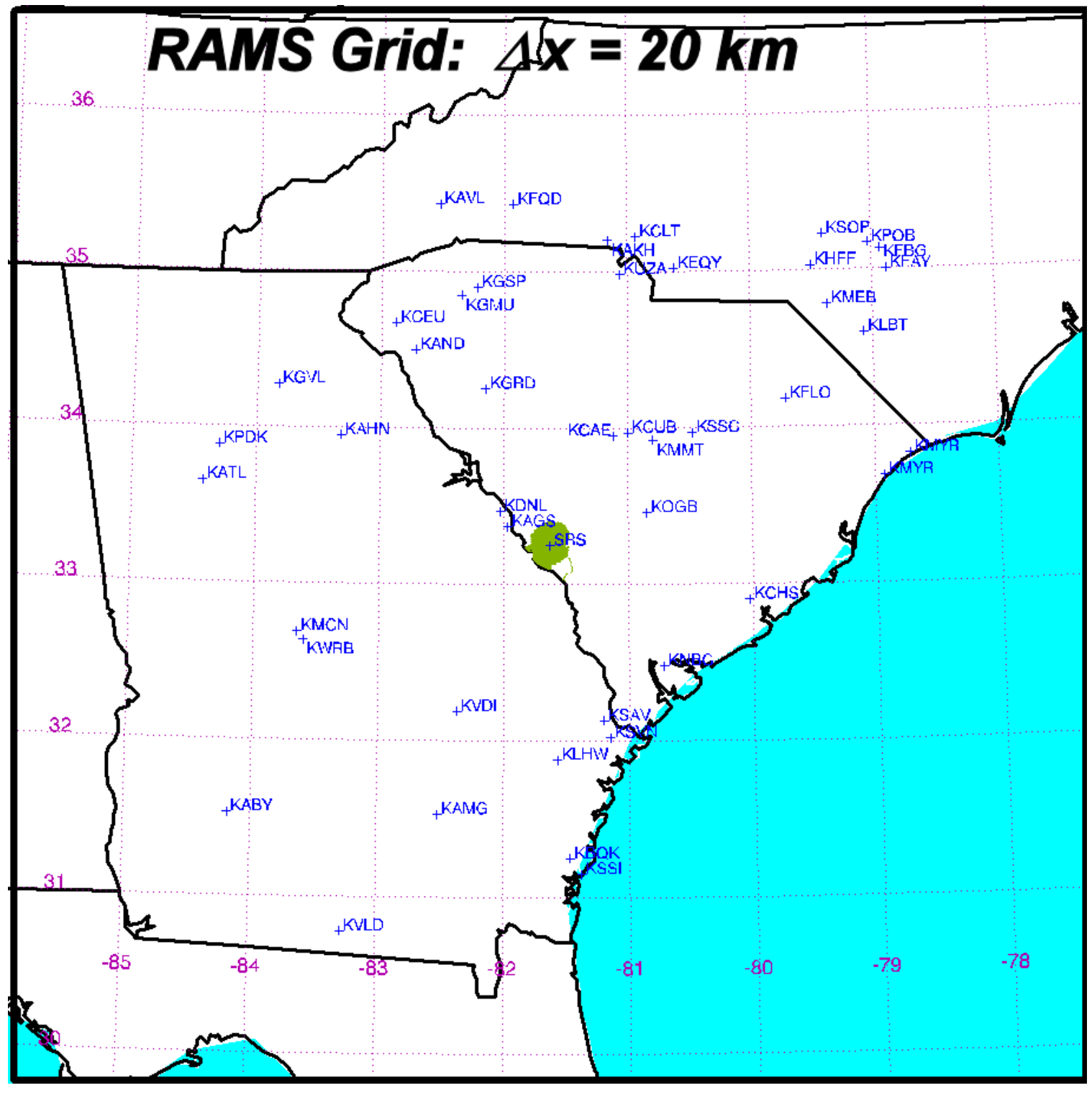


Figure 2. Model Comparisons at Station SRS

\begin{tabular}{|c|c|}
\hline 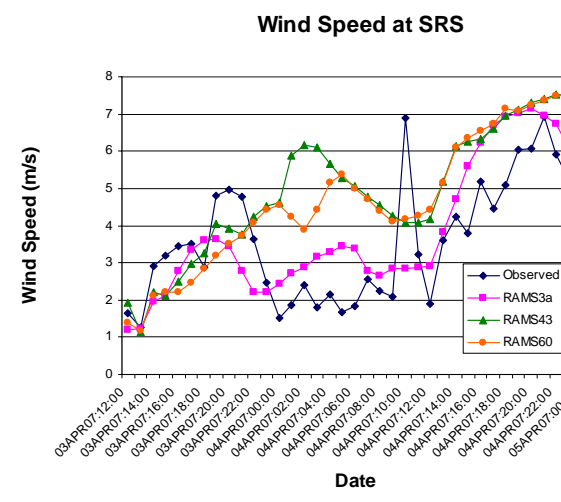 & Wind Speed at SRS \\
\hline 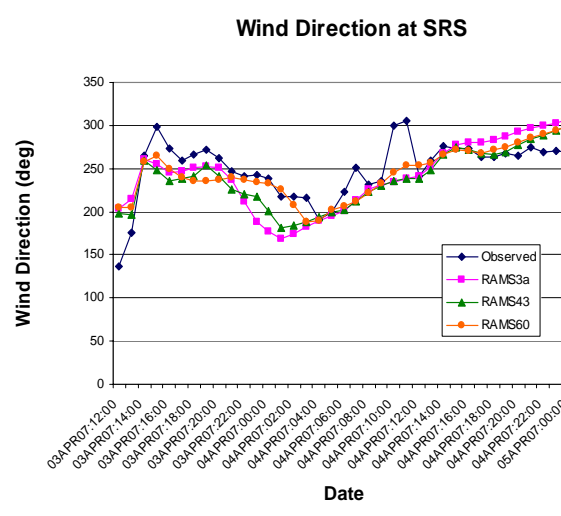 & $\begin{array}{llll} & \text { Wind Direction at SRS } \\
\end{array}$ \\
\hline 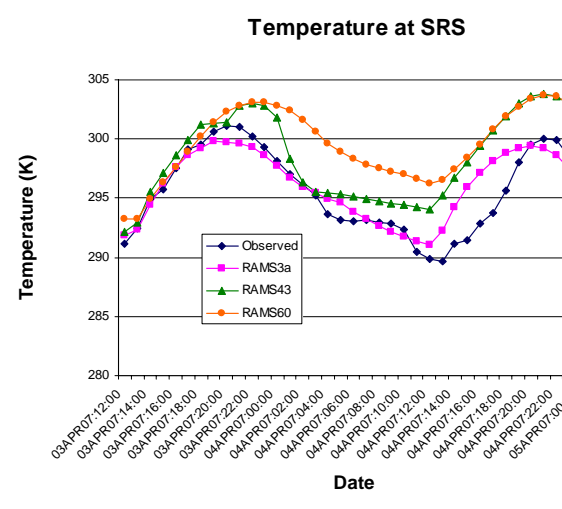 & 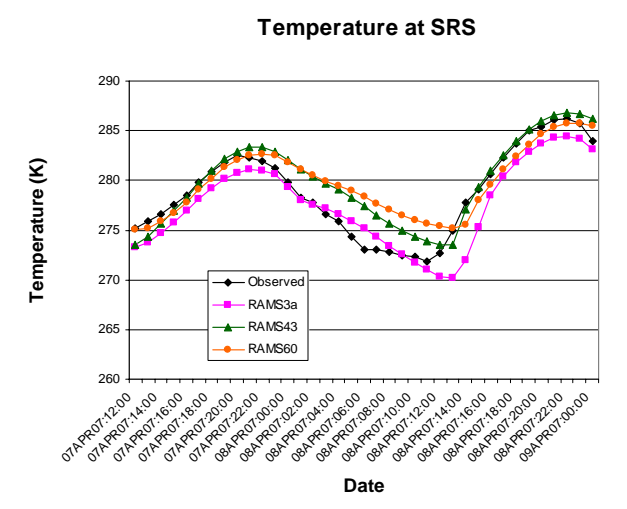 \\
\hline $\begin{array}{l}\text { Dew Point Temperature at SRS } \\
\end{array}$ & $\begin{array}{llll}\text { Dew Point Temperature at SRS } \\
\end{array}$ \\
\hline
\end{tabular}


Figure 3. Model Comparisons at Station KAGS

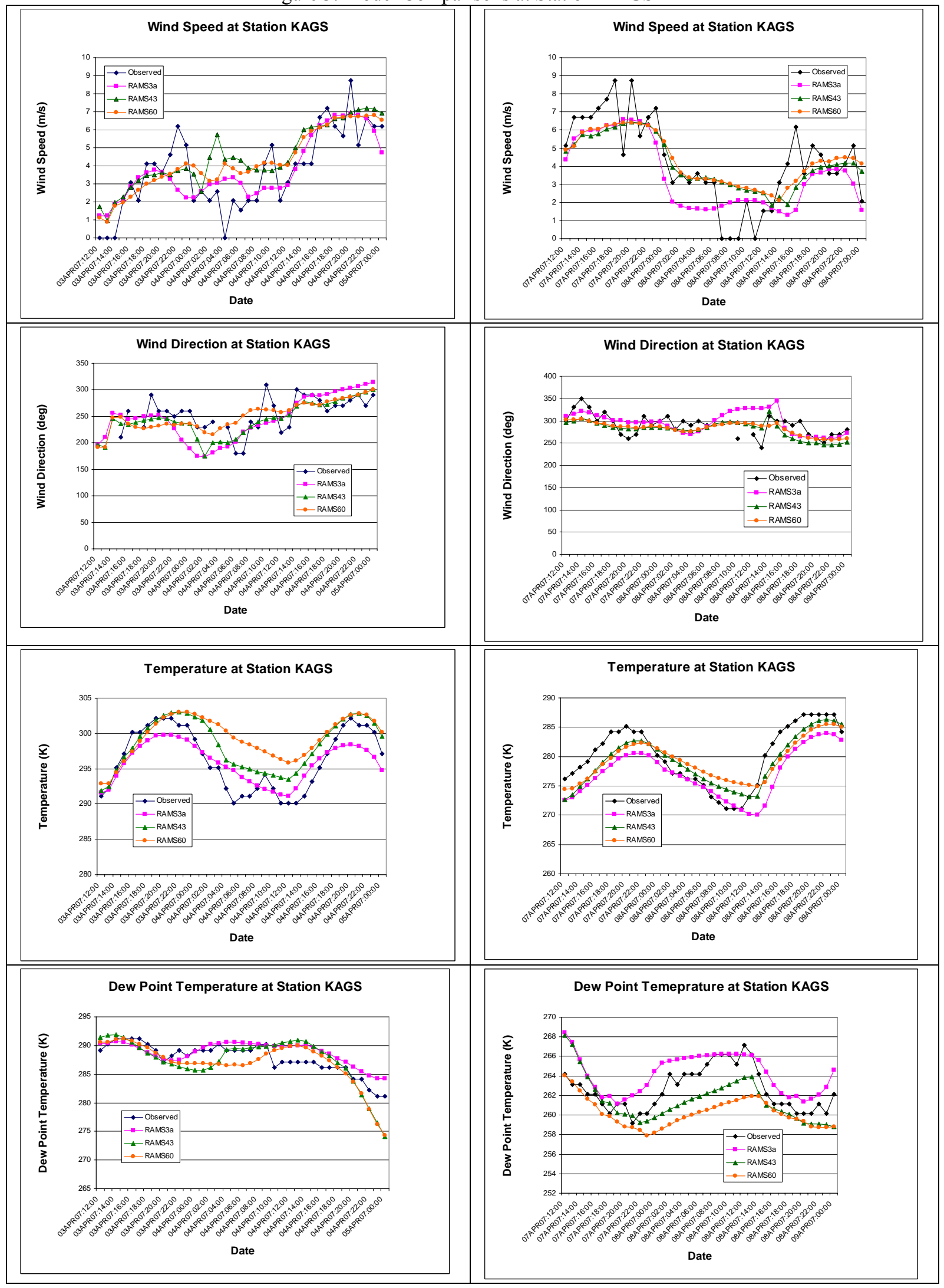


Figure 4. Model Comparisons at Station KDNL

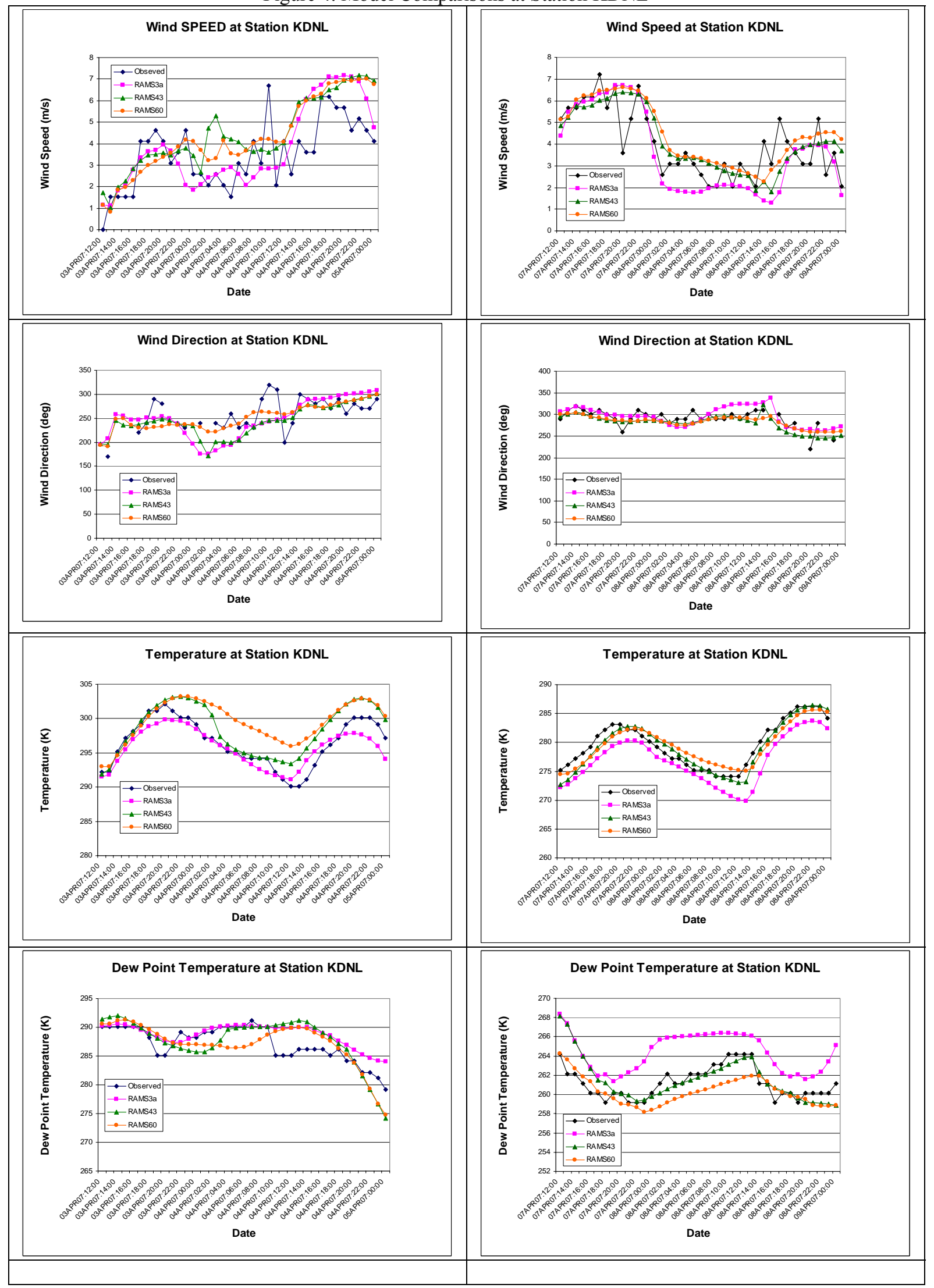


Figure 5. Model Comparisons at Station KMCN

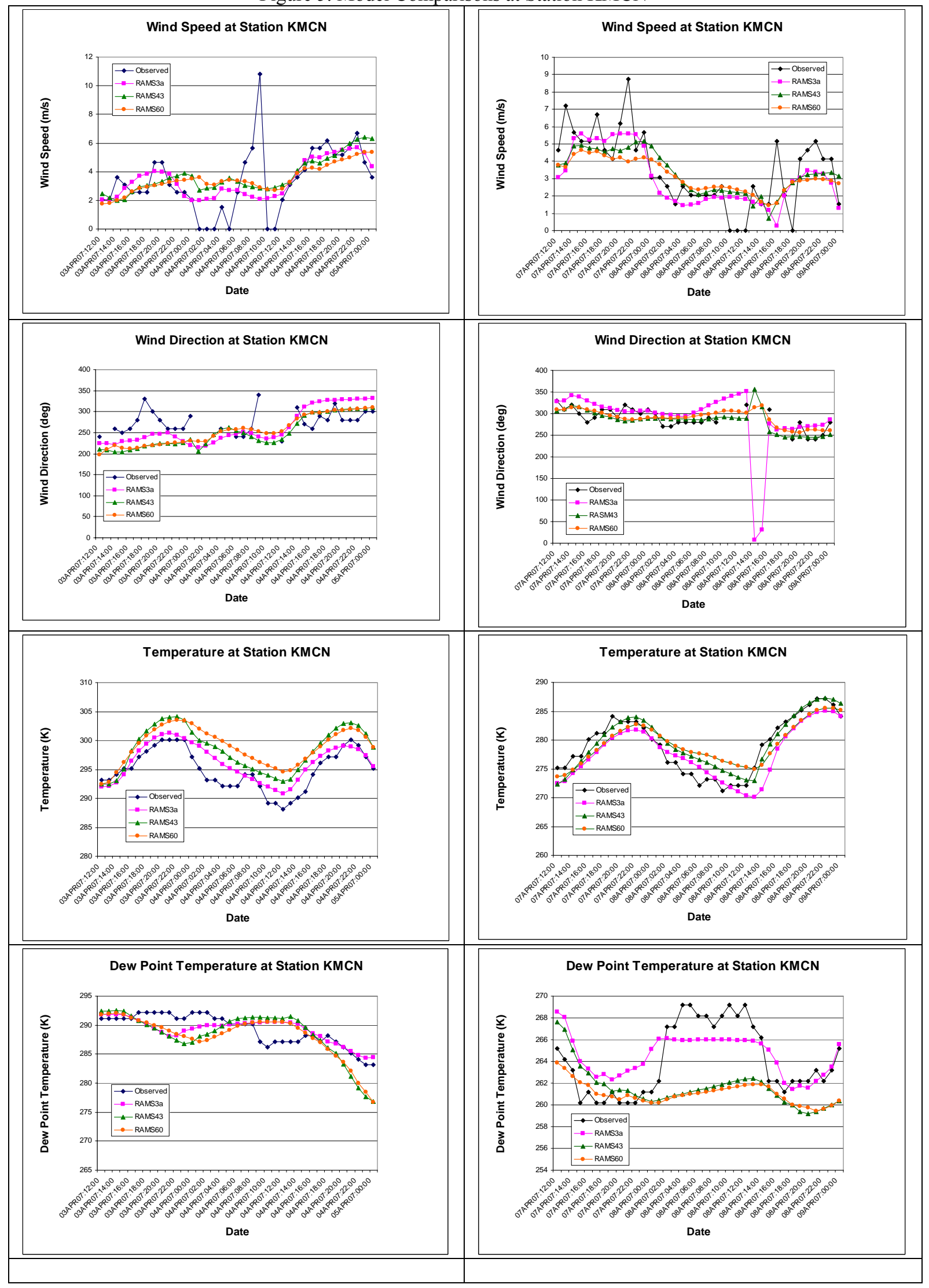


Figure 6. Model Comparisons at Station KATL

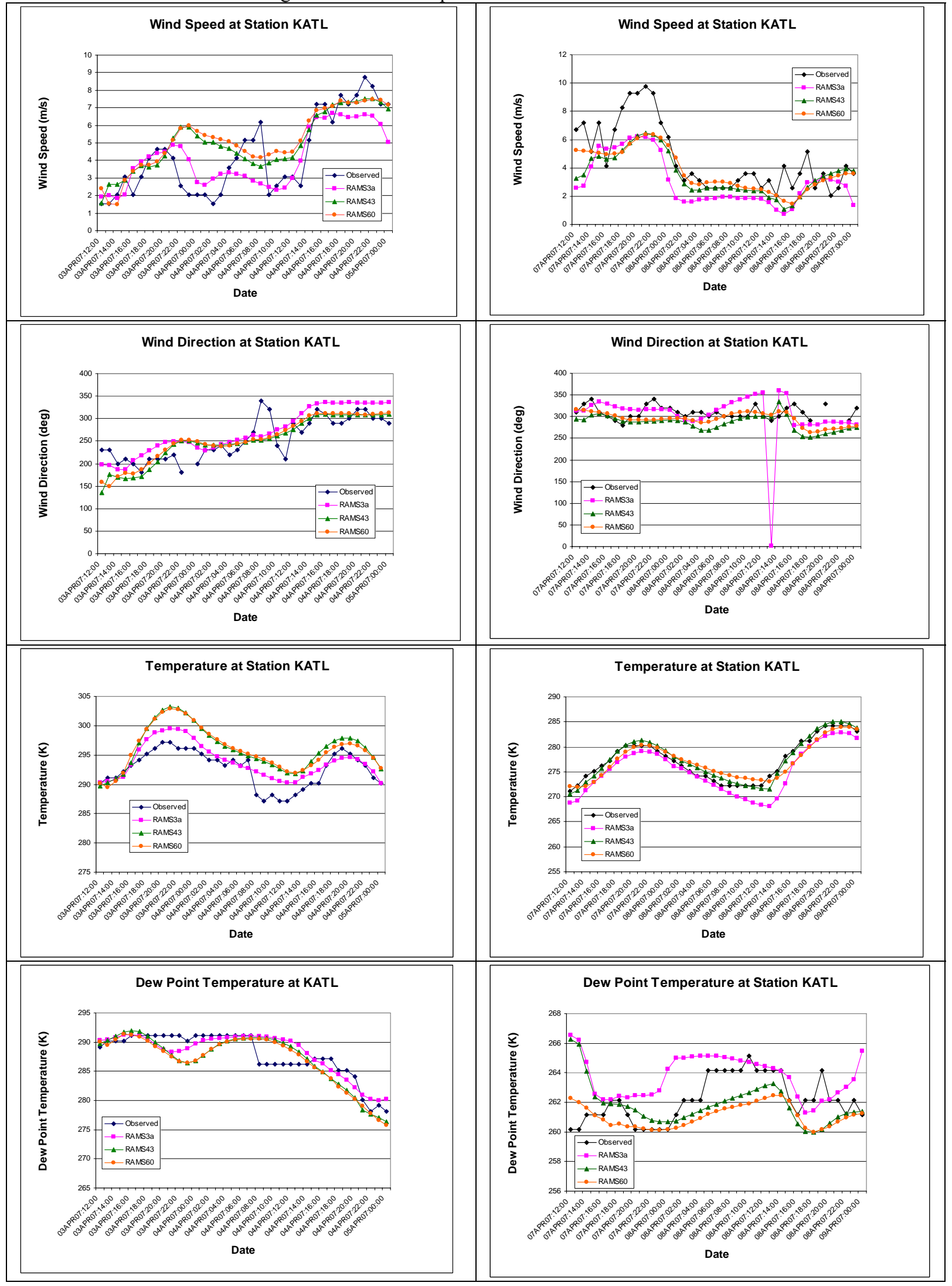


Figure 7. Model Comparisons at Station KCAE

\begin{tabular}{|c|c|}
\hline Wind Speed at Station KCAE & 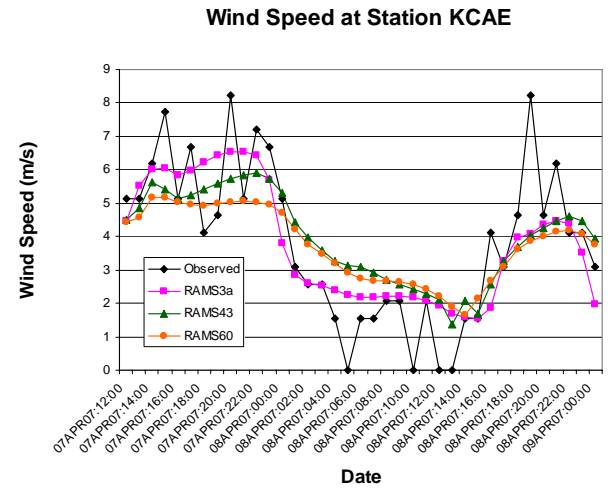 \\
\hline \begin{tabular}{lll}
\multicolumn{1}{c}{ Wind Direction at Station KCAE } \\
\end{tabular} & 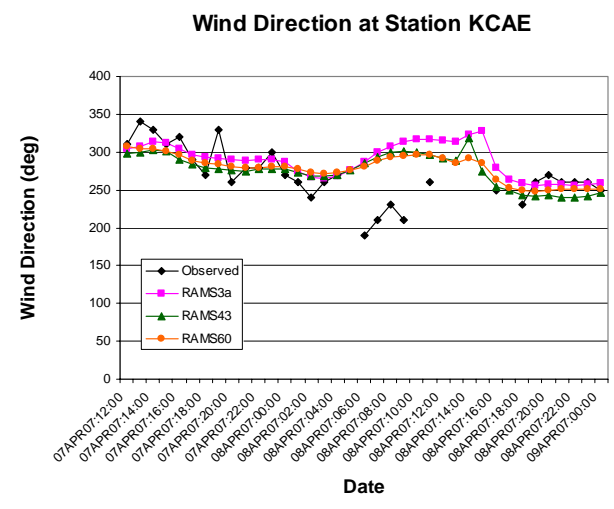 \\
\hline 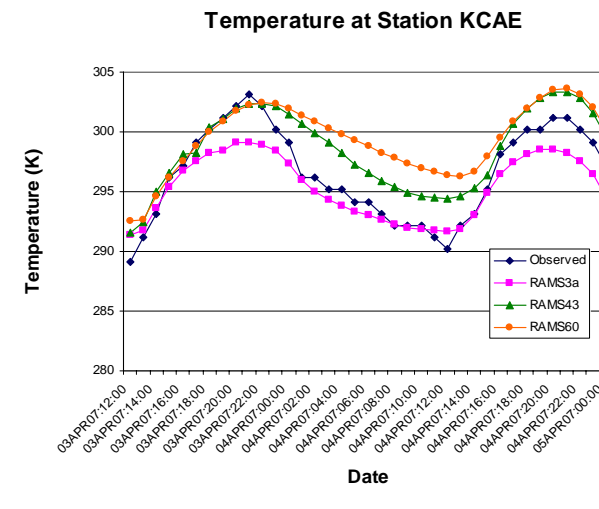 & Temperature at Station KCAE \\
\hline 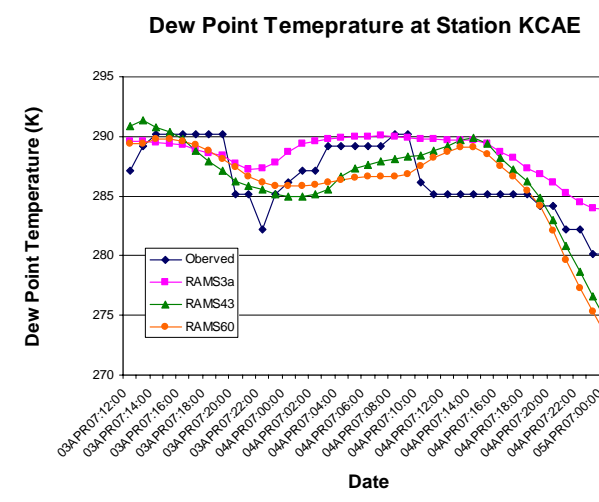 & Dew Point Temperature at Station KCAE \\
\hline
\end{tabular}


Figure 8. Model Comparisons at Station KCHS

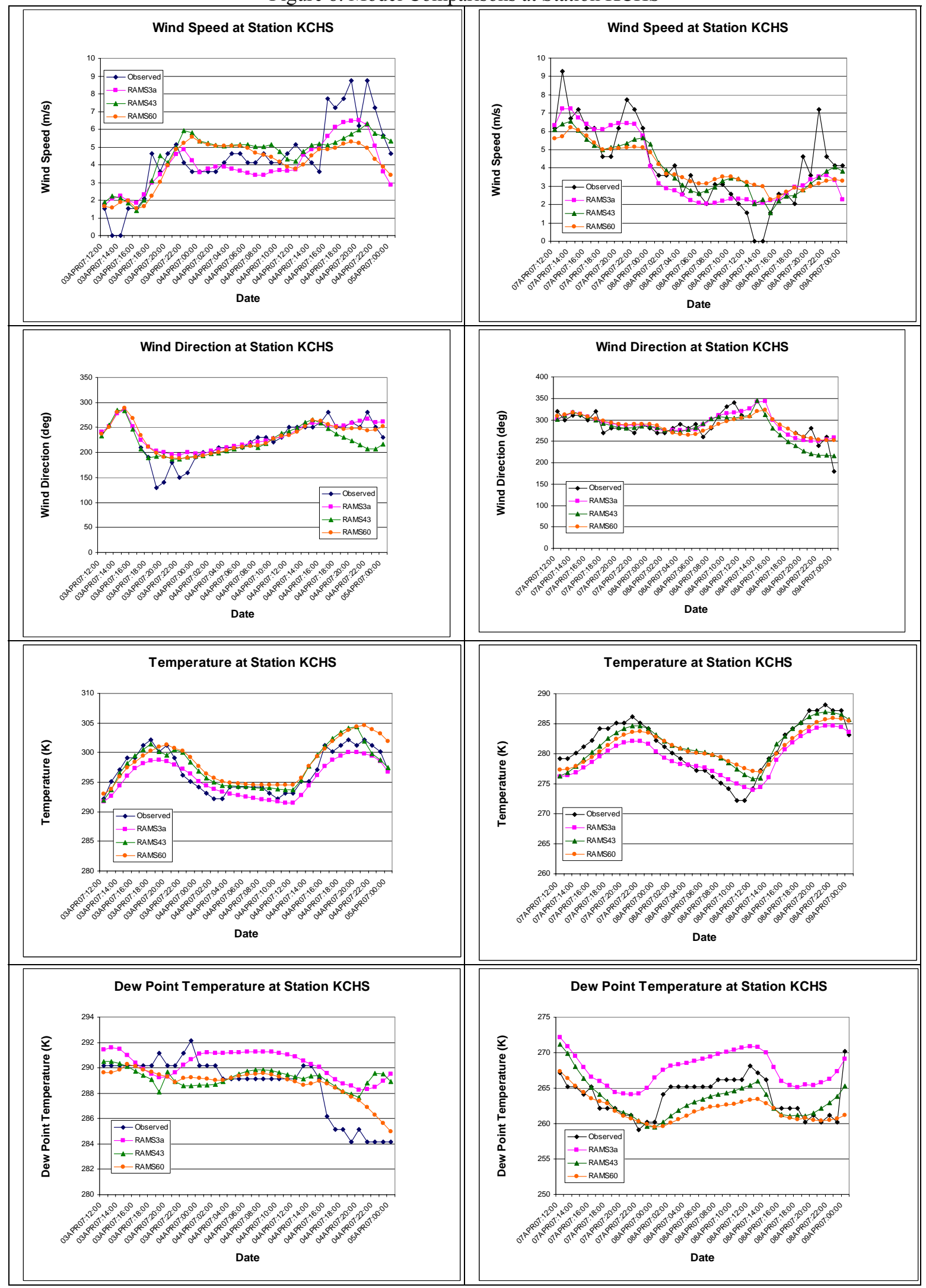


Figure 9.

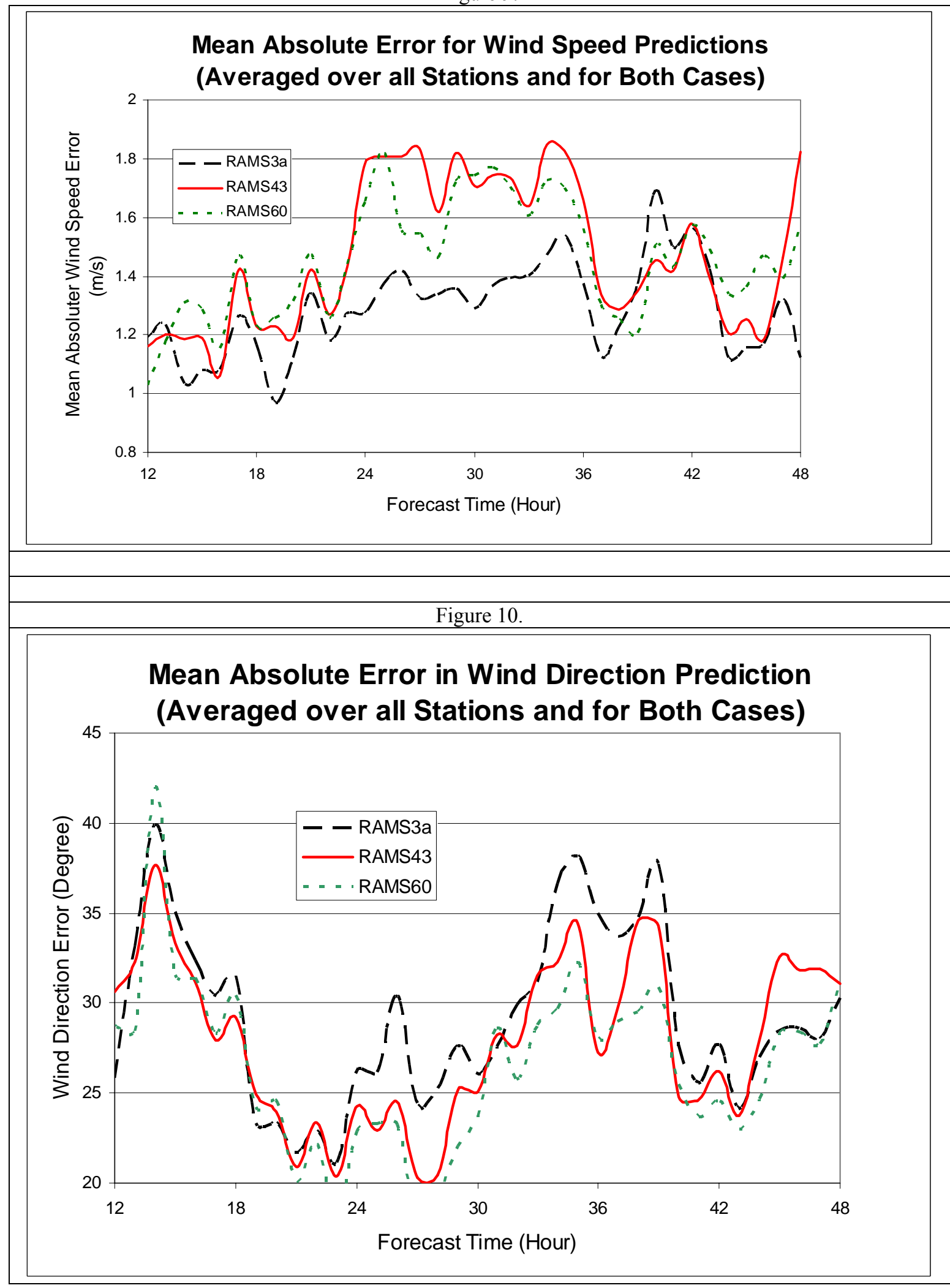


Figure 11.

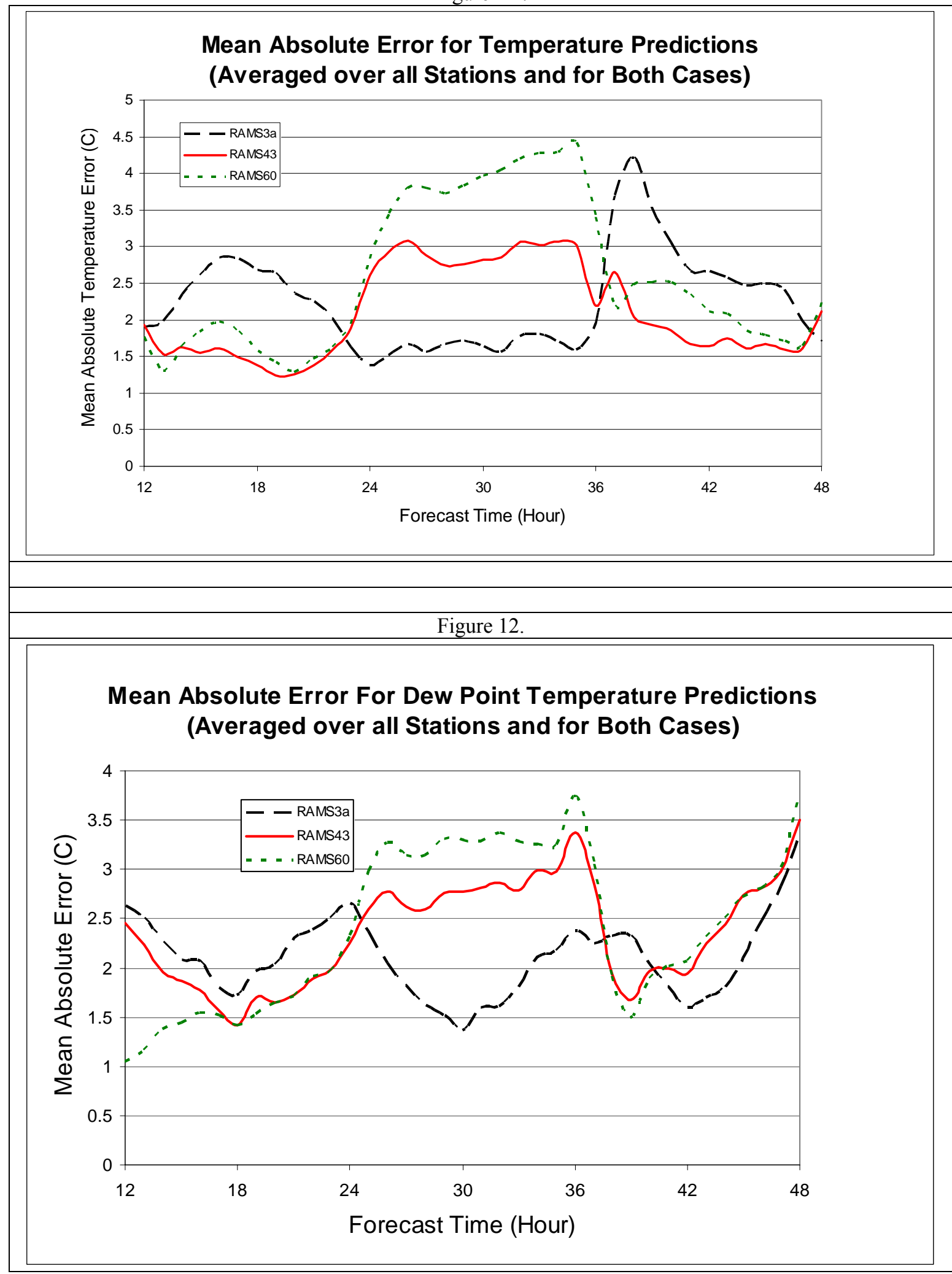


Figure 13.

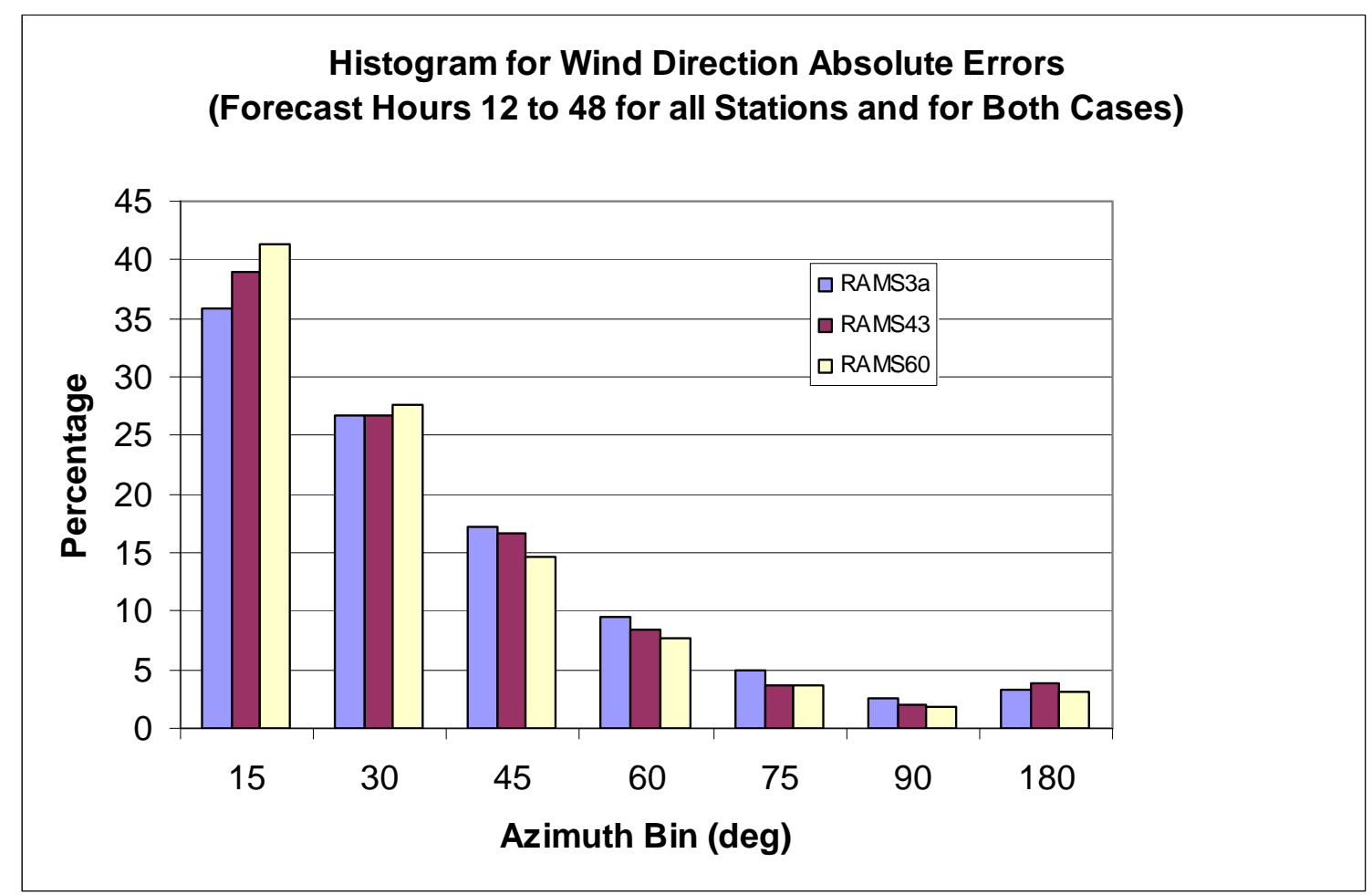


Figure 14. Mean Errors and Standard Deviations $( \pm \sigma)$ for Wind Speed Predictions (Forecast Hours 12 to 48 and all Stations)

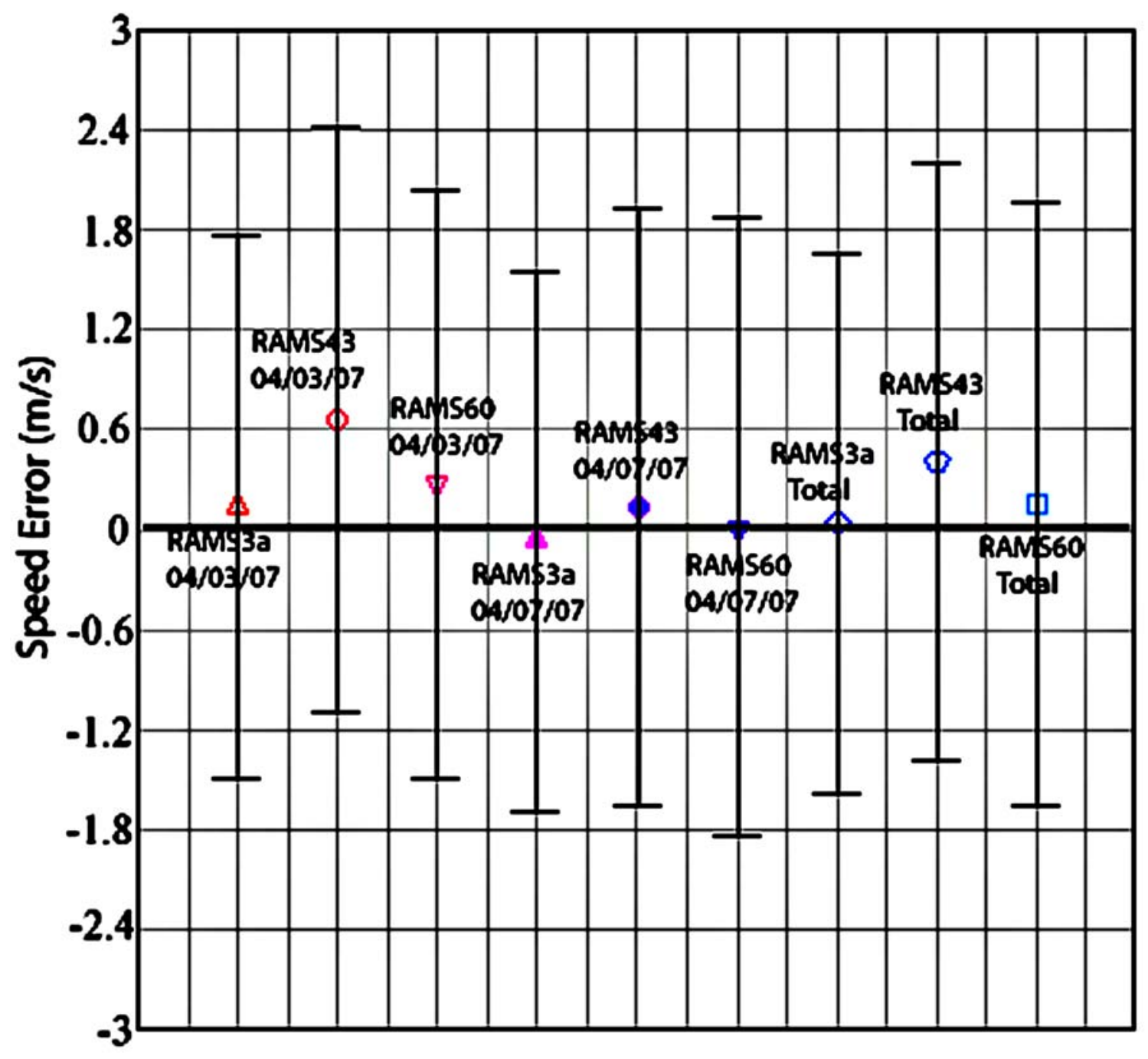


Figure 15. Mean Errors and Standard Deviations $( \pm \sigma)$ for Wind Direction Predictions

(Forecast Hours 12 to 48 and all Stations)

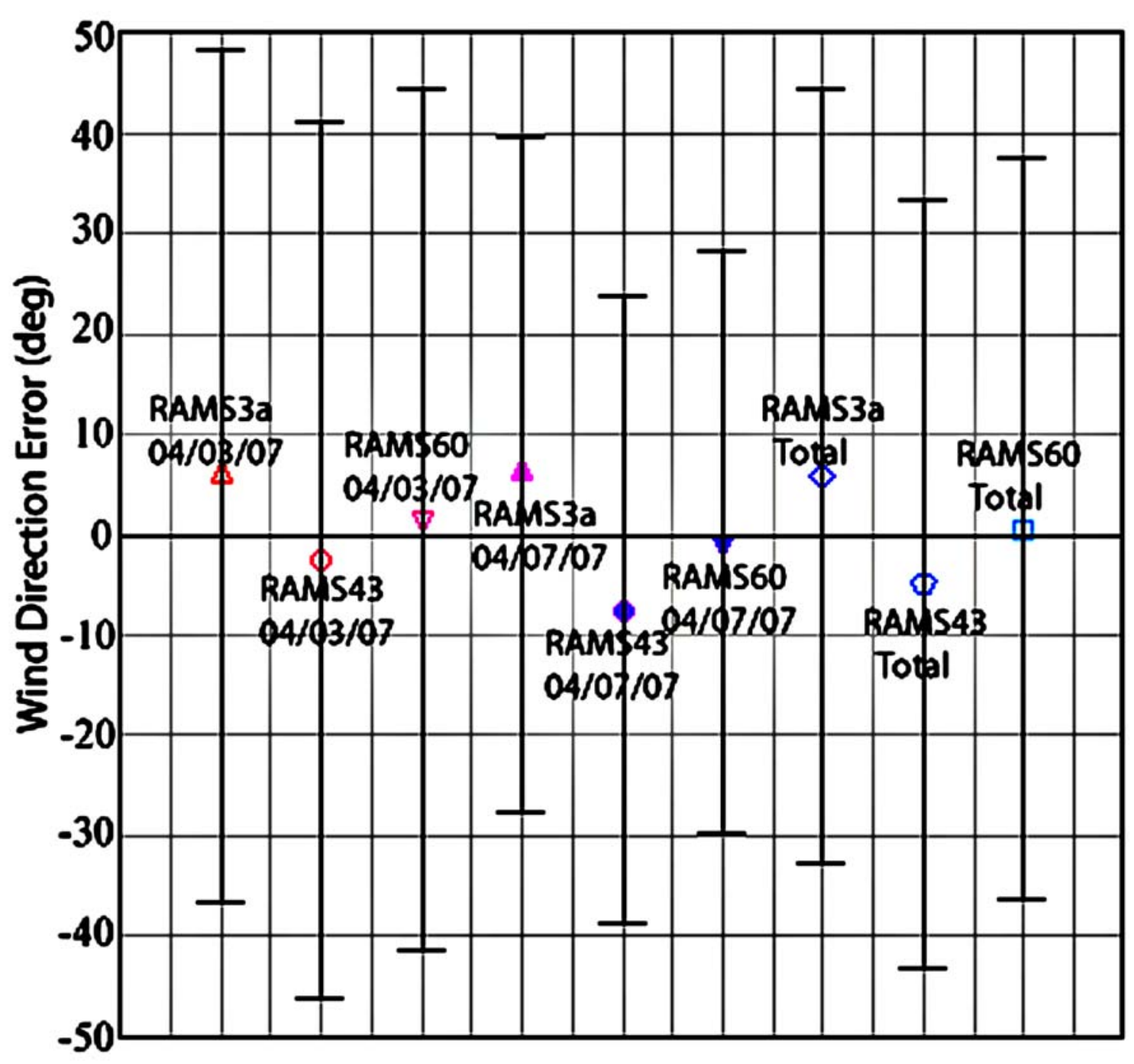


Figure 16. Mean Errors and Standard Deviations $( \pm \sigma)$ for Temperature Predictions

(Forecast Hours 12 to 48 and all Stations)

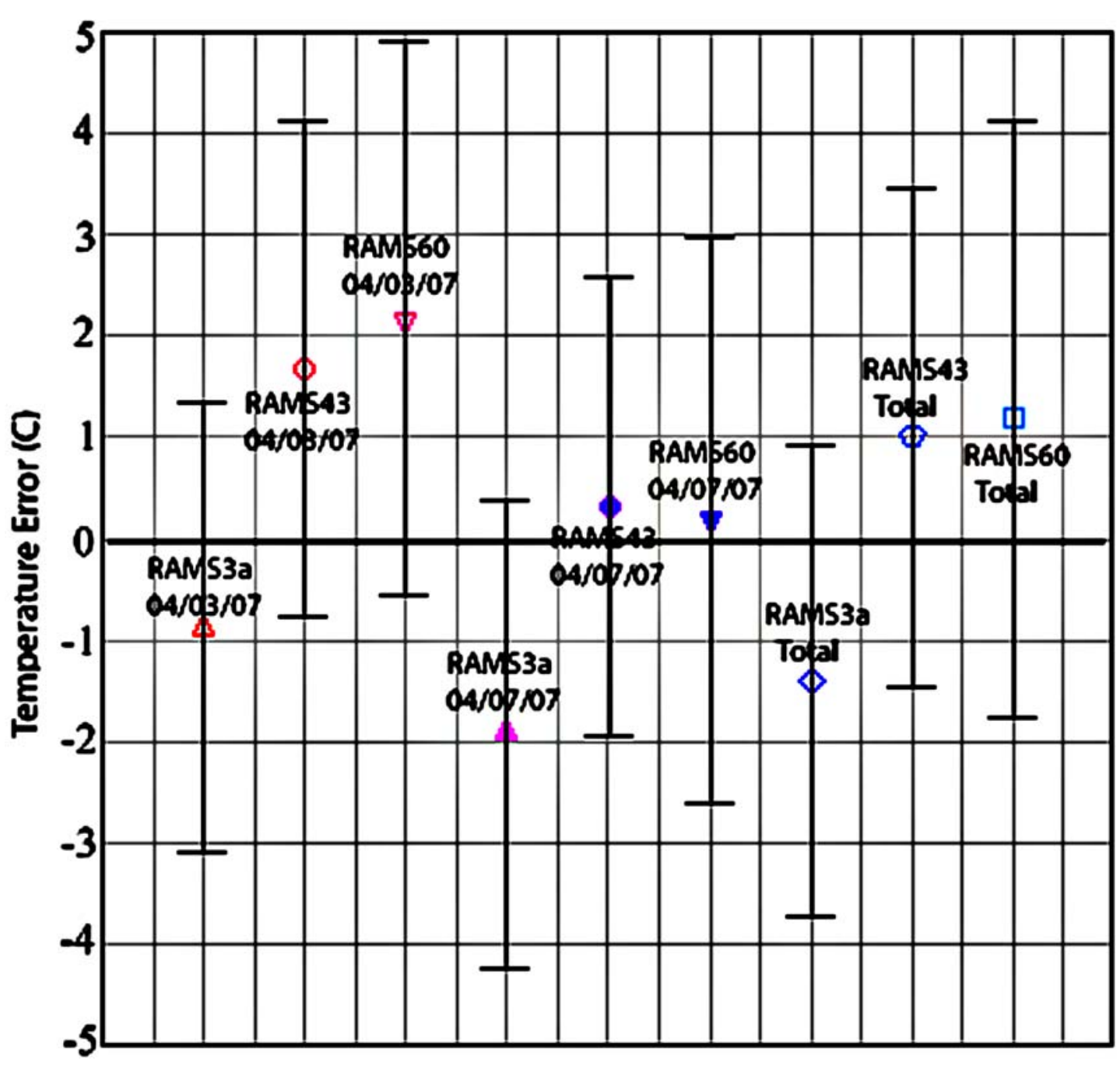


Figure 17. Mean Errors and Standard Deviations $( \pm \sigma)$ for Dew Point Predictions (Forecast Hours 12 to 48 and all Stations)

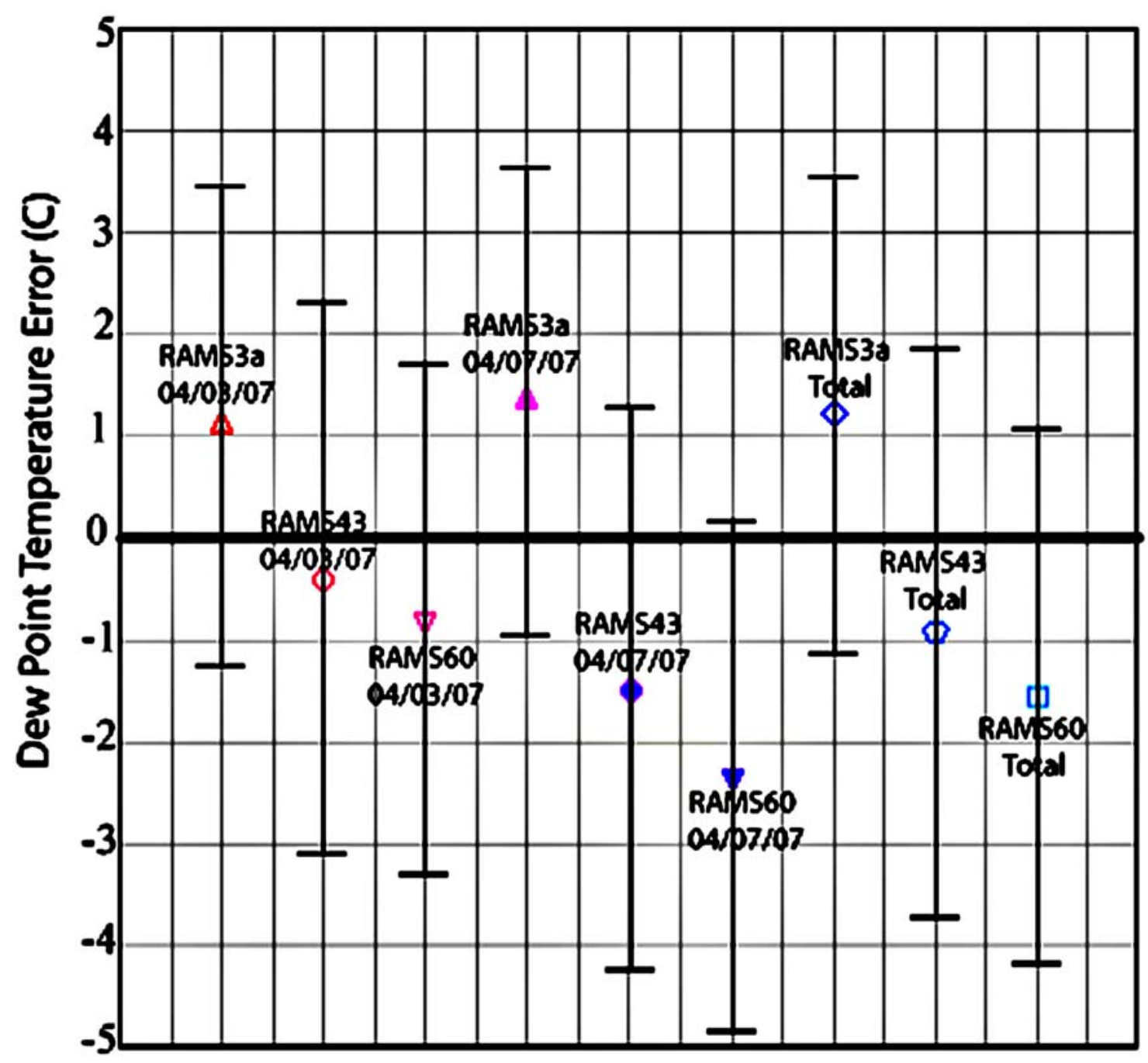


Figure 18.

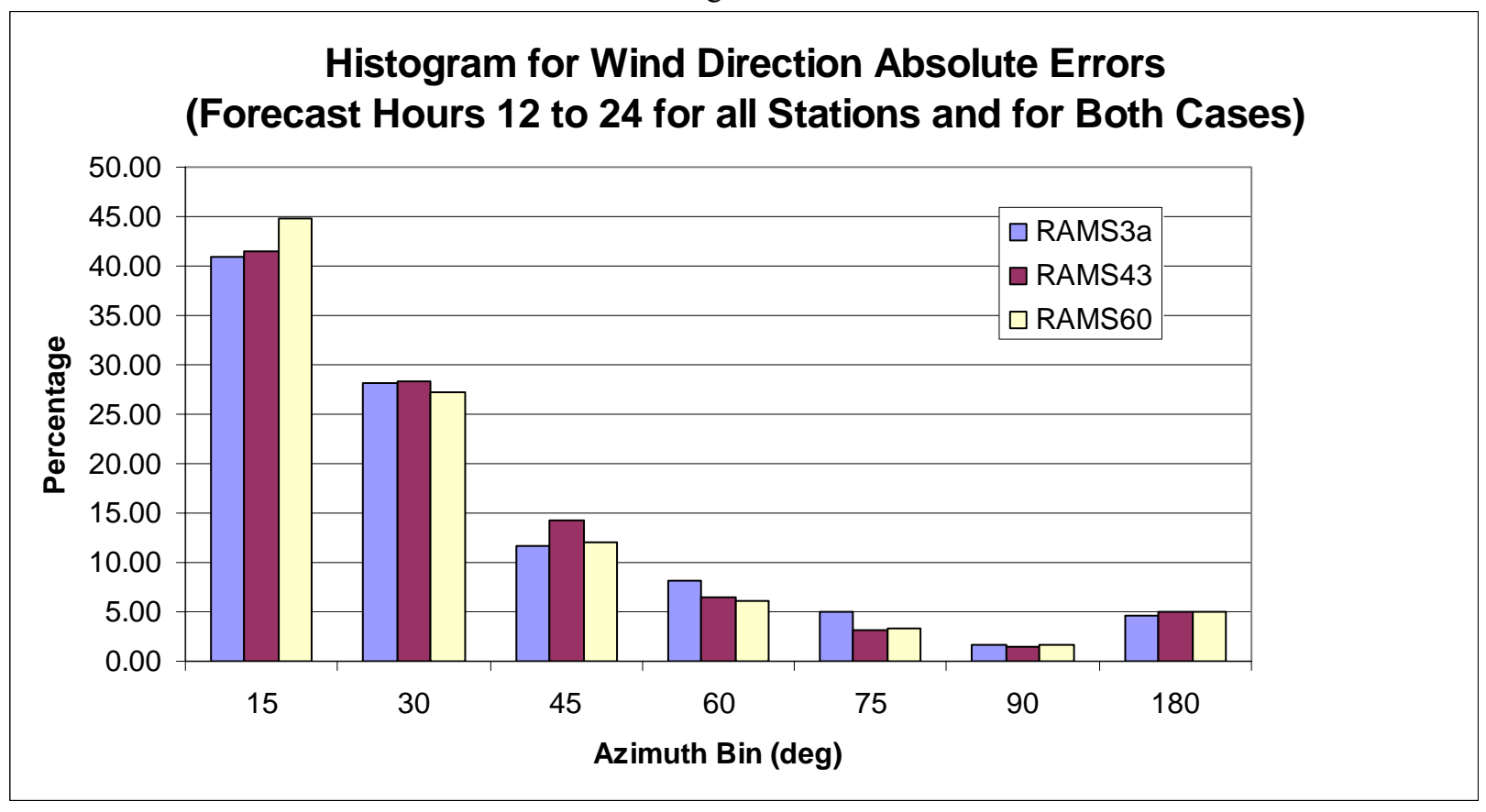


Figure 19. Mean Errors and Standard Deviations $( \pm \sigma)$ for Wind Speed Predictions (Forecast Hours 12 to 24 and all Stations)

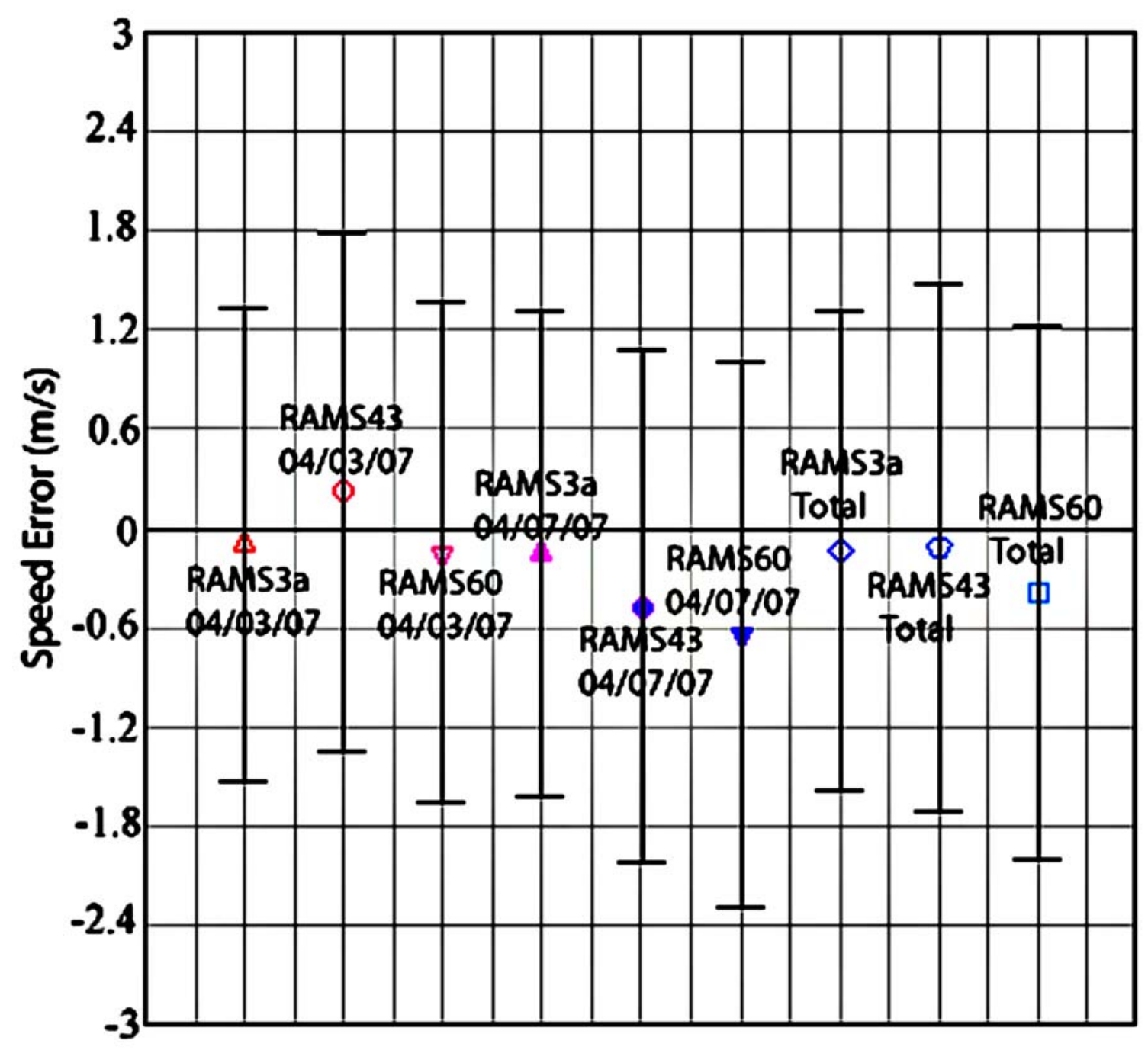


Figure 20. Mean Errors and Standard Deviations $( \pm \sigma)$ for Wind Direction Predictions (Forecast Hours 12 to 24 and all Stations)

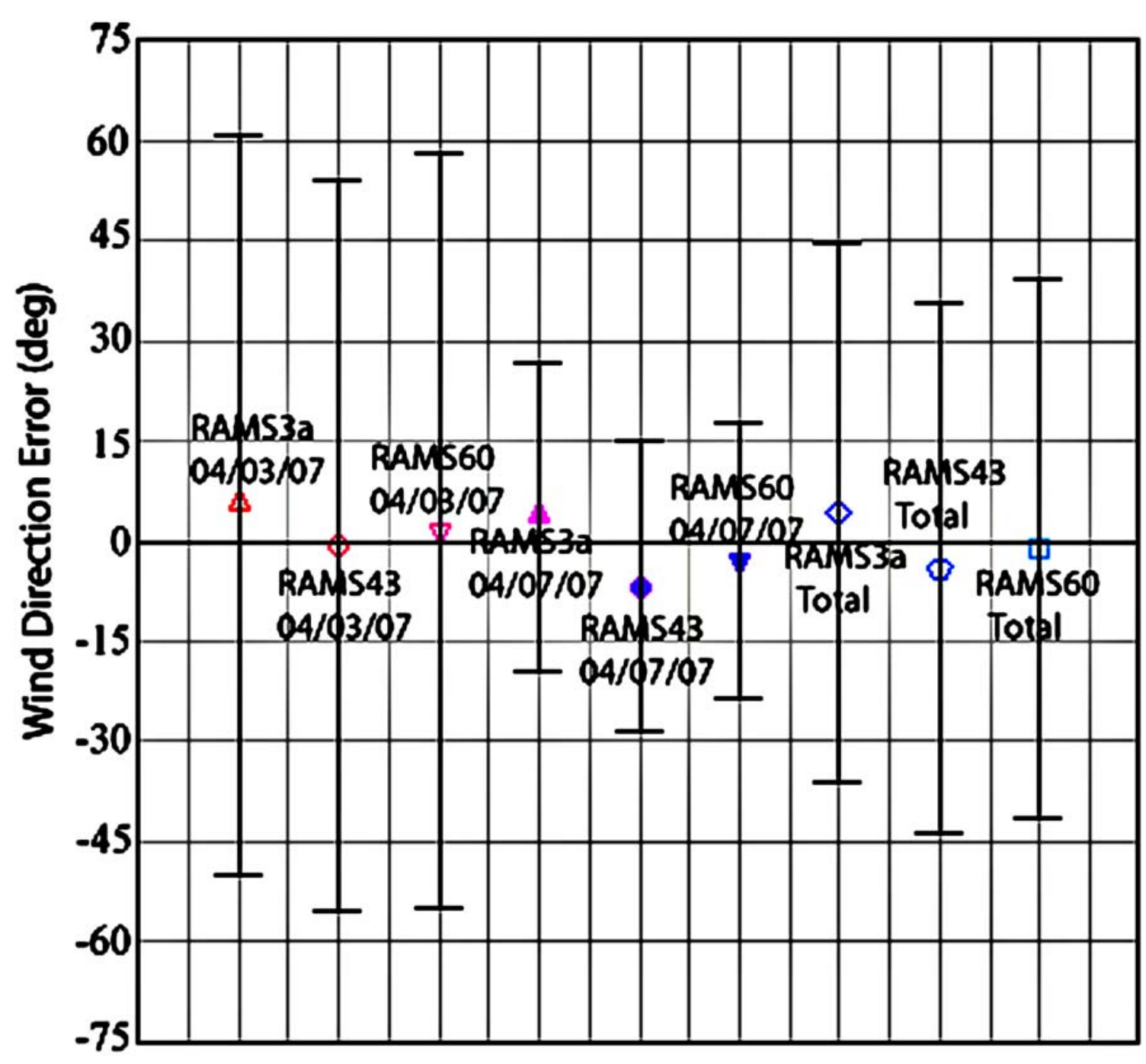


Figure 21.

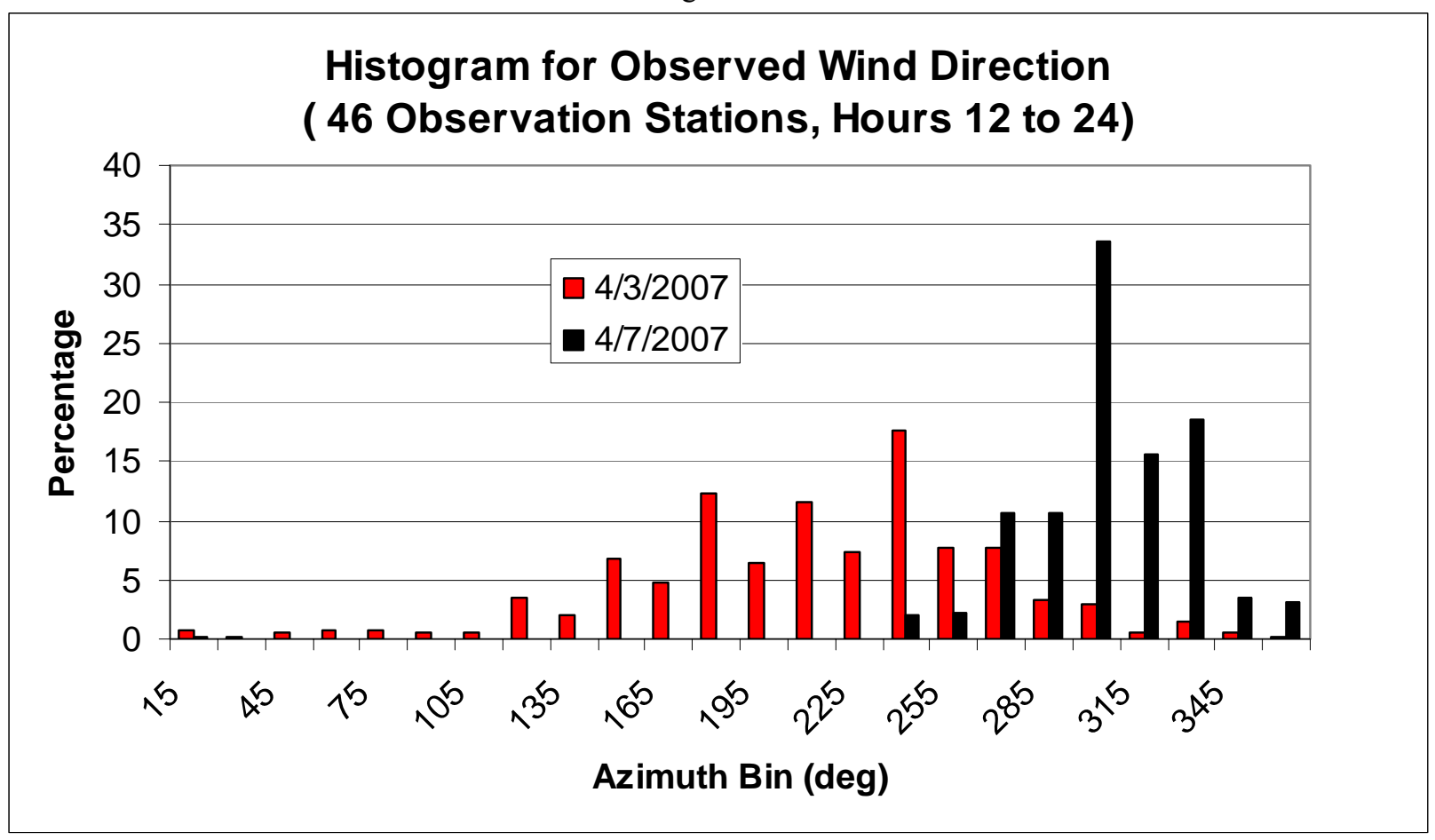


Figure 22. Mean Errors and Standard Deviations $( \pm \sigma)$ for Temperature Predictions (Forecast Hours 12 to 24 and all Stations)

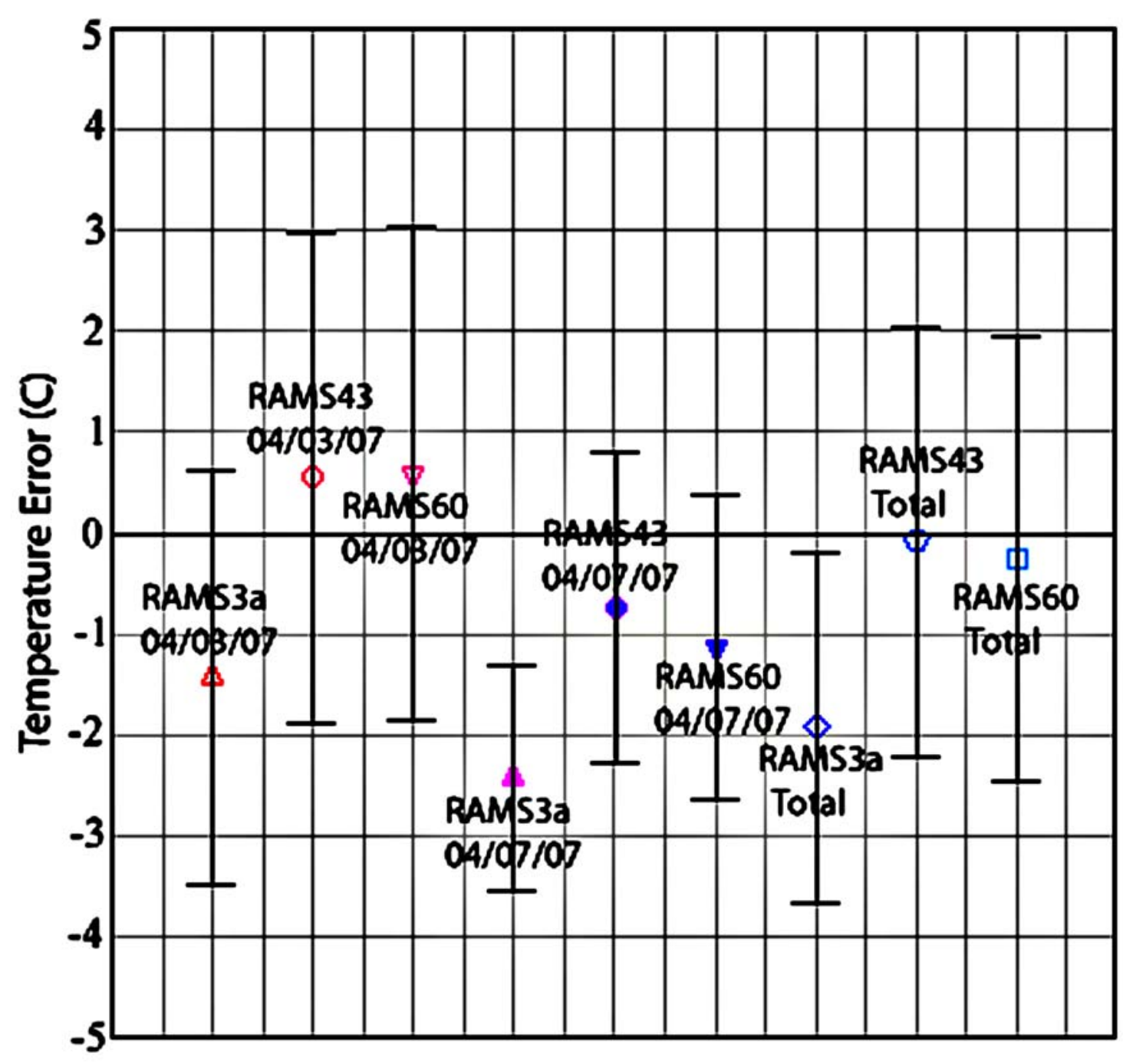


Figure 23. Mean Errors and Standard Deviations $( \pm \sigma)$ for Dew Point Predictions (Forecast Hours 12 to 24 and all Stations)

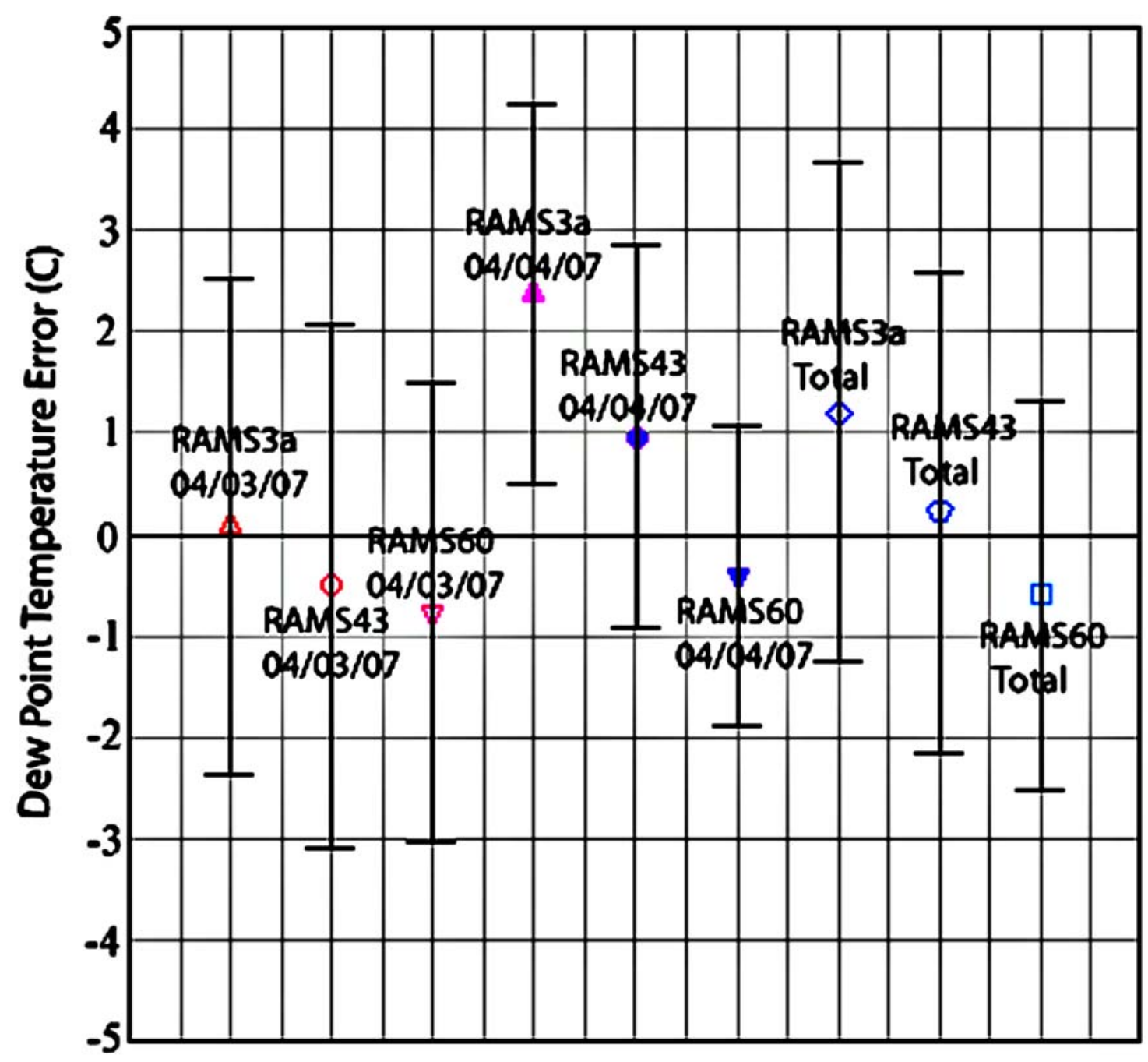


DISTRIBUTION

\section{SAVANNAH RIVER SITE}

R. P. Addis, 773-A

R. L. Buckley, 773-A

Kuo-Fu Chen, 773-A

D. P. Griggs, 735-A

C. H. Hunter, 773-A

R. J. Kurzeja, 773-A

B. L. O'Steen, 773-A

M. J. Parker, 773-A

NTS Records (5), 773-A 